\title{
4. Assessing Access to Information in Australia: The impact of freedom of information laws on the scrutiny and operation of the Commonwealth government
}

\author{
Daniel Stewart
}

When the first freedom of information (FOI) legislation was introduced in Australia, its basic objectives were said to be 'simple' (The Freedom of Information Bill 1978, second reading speech, Senator P. D. Durack, 9 June 1978): ${ }^{1}$ to make public the structure, functions and rules applied by government, and entitle members of the public to access government documents unless there are special reasons not to. Over 30 years later, the introduction of the 'most significant overhaul of the Freedom of Information Act 1982 (Cth) (the FOI Act) since its commencement' referred to the same basic objectives, attempting to 'deliver more effective and efficient access to government information and promote a culture of disclosure across government' (Freedom of Information Amendment (Reform) Bill 2009, second reading speech, Anthony Byrne MP, Parliamentary Secretary to the Prime Minister, Parliamentary Debates, 26 November 2009). This chapter explores the development, interpretation and operation of the FOI Act over the intervening 30 years. It examines the role of the FOI Act within the broader legal framework regulating access to government information to assess its impact on government policy at the Commonwealth level. It suggests that achieving the objectives of the FOI Act has proven anything but simple.

The Australian Freedom of Information Bill 1978 was the first of its sort introduced in a Westminster-style democracy. ${ }^{2}$ By the time it was enacted, Australia's contemporaries in Canada and New Zealand had also passed similar legislation. Other countries, including the UK, have since passed legislation emboldened by these early examples, and there has been a recent explosion of laws intended to provide access to government information in over 76 countries around the world (Ackerman and Sanoval-Ballesteros 2006, p. 86; Worthy 2010,

\footnotetext{
1 Unusually the second reading speech was not read out in Parliament but merely incorporated into Hansard prior to the parliamentary recess. The rush to have it introduced in this way in an attempt to quicken its passage proved pointless, however. See the discussion of the history of the Freedom of Information Act 1982 (Cth) below.

2 Note that the Swedish Freedom of the Press Act 1766 is usually referred to as the first FOI legislation that inspired the United States 1966 legislation: see Lamble 2002.
} 
pp. 561-582). However, despite this proliferation of access to information laws, our understanding of their impact is still developing (Worthy and Hazell 2010, p. 352).

Much of the assessment of the impact of government disclosure laws attempts a comparative evaluation of various elements or decisions made under FOI legislation. These comparisons are often based on high level indicators or aggregated data, often supplied by government agencies charged with administering or championing the Act, and suffer from ensuring the collection and aggregation of data are sufficiently rigorous and coordinated. ${ }^{3}$ Descriptive summaries of the presence of various exogenously valued features within legislation are contrasted with other studies attempting to compare the practical operation of access laws through lodgement of standardised requests. Some groups have also focused on the utility of access laws to their specific interests, particularly journalists (Worthy 2010, p. 562). Questions arise as to the objective value of the criteria used as the basis of the comparison (see Hazell, Worthy and Glover 2010, pp. 51-52).

The operation of access laws also presents other important impediments to evaluation. Access to information laws, perhaps more than comparable forms of regulation, 'do not operate in a vacuum' (Julnes and Holzer 2001, p. 696). The political context in which the access laws operate can have significant effects on the operation of reform initiatives. The attitude or culture of government agencies can make a significant difference. The goals of access laws are often vague, generalised or uncertain, making assessment inherently subjective or incommensurate. Perhaps most importantly, where those goals relate to democratic ideals or enhancing societal governance generally, they are profoundly impacted by the operation of institutions at the legislative, government, judicial or electoral level (Julnes and Holzer 2001, p. 696; see also Moynihan and Pandey 2004, p. 431).

Any assessment of the impact of access laws involves reference to the objects or justifications for such laws. Justifications for greater access to government information include both consequentialist and deontological approaches. Exposure of government information is claimed to provide greater accountability and encourages better decision-making. Greater transparency in the decisionmaking process establishes responsibility for the decision, requires disclosure of the considerations involved in the decision and increases the range of interests consulted. Requiring access encourages efficiencies in record-keeping and information gathering processes, improving the responsiveness of consultation and enabling correction of incorrect or incomplete information. Transparency can also encourage greater institutional legitimacy or trust, preventing corruption and

3 See, for example, the admission that the list of bodies subject to the FOI Act collected in the 2010 Annual Report is contributed by individual departments and is not authoritative: O'Connor 2010, p. 132. 
reducing rent-seeking, reducing costs associated with establishing or enforcing agreements or encouraging compliance and generally allowing for more effective implementation of public policies (Ackerman and Sanoval-Ballesteros 2006, p. 92).

Access to government information can also facilitate effective business practices. It has been suggested that

[c]ommercial users are, in many countries, one of the most significant user groups. Public bodies hold a vast amount of information of all kinds, much of which relates to economic matters and which can be very useful for business. A right to information helps promote a fluid information flow between government and the business sector, maximising the potential for synergies. This is an important benefit of the right to information legislation, and helps answer the concerns of some governments about the cost of implementing such legislation (Mendel 2008, pp. 4-5).

Many of the consequentialist arguments above can relate generally to transparency in its various manifestations, in both the public and private sectors. However, justifications for transparency of government information in particular often relate to the contribution to participatory democracy. Participation at any level of the democratic process requires access to and an understanding of information about the activities of government. Engagement with the political process beyond exercising voting rights requires an awareness of the impact of government decisions and the interests they reflect. The ability to access, respond to and augment information utilised in the decision-making process in turn raises the level of political debate and more informed decisionmaking (Hazell, Worthy and Glover 2010, p. 87).

The rise of access to information laws has also been linked with its acceptance as an integral element of freedom of speech and as part of a general right to information. Such rights are based on realising our potential as citizens in a democratic society. For example, Mark Bovens suggests that information rights such as access to information

concern first and foremost the social functioning of citizens, not only in relation to the public authorities, but also in their mutual relations and their relations with private legal entities. Information rights should be part of the civil rights chapter of constitutions, together with the other individual rights (Bovens 2002, p. 327).

With the right to information comes the correlative responsibility to participate in holding government to account (Roberts 2001, p. 243). Thus access to information is justified not just through the instrumental effects on the various participants in government, but in defining and enhancing the relationship between government and citizen (see also Rosanvallon 2008, p. 1). 
The objects of the FOI Act were based on recommendations of the Senate Standing Committee for Legal and Constitutional Affairs into the first FOI Bill in 1979. They identified three specific justifications for freedom of information laws:

With certain national security exemptions ... we believe that every individual has a right to know what information is held in government records about him [sic] personally ... Second, we believe that when government is more open to public scrutiny, it in fact becomes more accountable ... The accountability of the government to the electorate, and indeed to each individual elector, is the corner-stone of democracy, and unless people are provided with sufficient information accountability disappears ... Thirdly, we believe that if people are adequately informed, and have access to information, this in turn will lead to an increasing level of public participation in the processes of policy making and government itself ... Unless information is available to people other than those professionally in the service of government, then the idea of citizens participating in a significant and effective way in the process of policy making is set at nought (SSCLCA 1979).

Thus even though these justifications focus on the instrumental effects of FOI laws they recognise the reciprocal nature of the obligations imposed, focusing not just on the accountability of government but also the importance of greater participation of individuals in the policy process.

The objects clause originally inserted as s.3 of the FOI Act only partially addressed these justifications. The object of the FOI Act was 'to extend as far as possible the right of the Australian community to access to information in the possession of the [Commonwealth] Government'. It then referred to three ways this was to be achieved: by 'making available to the public information about the operations of departments and public authorities'; 'creating a general right of access to information in documentary form in the possession of Ministers, departments and public authorities, limited only by exceptions and exemptions necessary for the protection of essential public interests and the private and business affairs of persons'; and 'creating a right to bring about the amendment of records containing personal information that is incomplete, incorrect, out of date or misleading'. Subsection 3(2) then suggested:

It is the intention of the Parliament that the provisions of this Act shall be interpreted so as to further the object set out in subsection (1) and that any discretions conferred by this Act shall be exercised as far as possible so as to facilitate and promote, promptly and at the lowest reasonable cost, the disclosure of information. 
The objects clause therefore recognised the general rights of access and amendment but without reference to the accountability and participation these rights are expected to achieve. It wasn't until the recent 2010 amendments (Freedom of Information Amendment (Reform) Act 2010 (Cth)) that the reciprocal operation of the FOI Act is recognised in its objects with an explicit statement:

s.3(2) The Parliament intends, by these objects, to promote Australia's representative democracy by contributing towards the following:

(a) increasing public participation in Government processes, with a view to promoting better-informed decision-making;

(b) increasing scrutiny, discussion, comment and review of the Government's activities.

The recent amendments also include 'recognition that information held by the Government is to be managed for public purposes, and is a national resource' ${ }^{4}$ Thus the objects of the amended FOI Act recognise the value that access to government information has in improving the relationship between government and individual and making greater utilisation of government information possible.

This chapter considers how effective the FOI Act has been in attaining these stated and unstated objectives. It attempts to describe the development and operation of the FOI Act, outlining the application of the major provisions of the legislation and the basis for calls for their reform. It explores the various tensions within the legislation, including the need to encouraging disclosure generally without entrenching the means for restriction of access; recognising the role of the public service as agents both of the government and the public generally; protecting the interest of the individual in the context of the collective benefits of disclosure; and balancing the long- and short-term costs and benefits of any access regime. Beyond these inherent tensions, however, this chapter also considers whether there might indeed be a more fundamental concern over the introduction and operation of the FOI Act: the focus in the FOI Act on providing a right to access to government information reinforces the separation between government and individual rather than enhancing the engagement of both in the process of policy-making.

Part I of this chapter reviews the development of the legal and political context in which the FOI was conceived and enacted, and how that context has continued to develop. Examining the legal framework of access to government information more broadly allows a consideration of the role of the FOI Act, both in the gaps it attempts to fill and the influence on the operation of that framework as a whole.

4 Freedom of Information Amendment (Reform) Act 2010 (Cth) introduced what is now s.3(3) of the FOI Act. 
Part I seeks to establish three propositions: existing legal restrictions motivated or encouraged resistance to the introduction of the FOI Act; introduction of the FOI Act did not have a significant effect on the development of other elements of the legal regulation of disclosure and may arguably have hindered further development; and any discussion of the impact of the FOI Act on government policy-making has to consider the legal and political context in which that reform took place.

Part II examines the history and operation of the FOI Act, in particular the impact that the utilisation of the exemptions to disclosure have had on achieving the objects of the FOI Act. It examines the way in which concerns over the impact of the FOI Act on conventions of responsible government manifested in a continuing reluctance to embrace the pro-disclosure culture that the FOI Act was seeking to achieve, and in particular the extent to which questions of deference to the judgement of the executive on the impact on the effective working of government undermined the potential contribution of the FOI Act.

Part III examines the role of the FOI Act in protecting the interests of individuals and organisations. It considers the operation of the FOI Act in facilitating access to personal information and the interaction with privacy concerns. It also considers the protection of confidential and business information. The role the FOI Act played in enhancing the trust in government commercial dealings and the impact that had on the scrutiny and enhancement of broader policy objectives is also discussed.

The final part of this chapter looks at other elements of the recent reforms to the FOI Act to consider their antecedents and possible effect on the ongoing impact of the FOI Act. In particular, it looks at the imposition of charges for access to government information and the inherent evaluation of costs and benefits such charges represent. It is suggested that some elements of that reform have the potential to substantially renew the relationship between government and citizen in the policy-making process, but concerns continue over the ability to carry out such a renewal given the history and operation of the FOI Act.

\section{Part I: The legal context of access to government information}

\section{Breaking down government secrecy?}

In the final months of 2010, Wikileaks, 'a non-profit media organization dedicated to bringing important news and information to the public', ${ }^{5}$ released over 250,000 US diplomatic cables to five respected international news organisations

5 As described on the Wikileaks website, which is located on varying servers, including http://213.251.145.96/. 
- New York Times, The Guardian, Der Spiegel, Le Monde and El Pais (see Benkler 2011, pp. 1-2). Those news organisations then helped sift through and publish a selection of cables, often in redacted form, with simultaneous release on the Wikileaks website. They continued to be released in stages. The release drew immediate calls for action to be taken to seek to prevent or discourage the release of what was claimed to be classified, highly sensitive or damaging material (BBC News 2010; Shane 2010; see also Benkler 2011). However, the consequences from the release have so far been less dramatic. As US Secretary of Defense Gates predicted at a Pentagon press briefing on the day of the release:

Now, I've heard the impact of these releases on our foreign policy described as a meltdown, as a game-changer, and so on. I think - I think those descriptions are fairly significantly overwrought. The fact is, governments deal with the United States because it's in their interest ... They will continue to work with us. We will continue to share sensitive information with one another. Is this embarrassing? Yes. Is it awkward? Yes. Consequences for U.S. foreign policy? I think fairly modest (US Department of Defence 2010).

A similar scenario, although on a smaller scale, had played out in Australia some 30 years earlier. An initial distribution of some 662 copies of a 437-page book reproducing diplomatic memoranda, assessments, briefings and cables had resulted in the purchase of less than 100 copies before an injunction was obtained to prevent further sales. Copies had been sold to the Commonwealth government as well as the Indonesian and US embassies. Copies of some of the cables were to be serialised in The Age newspaper. Again, the main concern was perhaps what the fact of release - rather than the actual content of the documents might mean for the relationship between Australia and the relevant countries concerned. As the secretary of the Department of Foreign Affairs suggested: 'It is much more likely to facilitate our future relations if the government has been seen to try its utmost to prevent that [disclosure] happening' (Commonwealth $v$ John Fairfax \& Sons (1980) 147 CLR 39 at 46).

An ex parte interim injunction was granted by Mason $\mathrm{J}$ in the High Court at 12.45 am on Saturday 8 November 1980, after the Commonwealth had become aware of the intended publication of the book and partial serialisation in The Age later that morning. It was too late to prevent distribution of an early edition of some 60,000 copies of the newspaper, or to prevent early sales of the book. In Commonwealth $v$ John Fairfax \& Sons, the Commonwealth government was successful in continuing the interim injunctions. However, the impact of the judgement was to significantly alter the ability of the government to keep secrets.

Mason $\mathrm{J}$ confirmed that protection of government material as confidential in Australia involved three elements: that the material to be protected was 
confidential in quality rather than public knowledge; that it was imparted in circumstances that imported an obligation of confidence; and that there will be unauthorised use of that information to the detriment of the party communicating it (Commonwealth $v$ Fairfax (1980) 147 CLR 39 at 51 citing Coco $v$ A.N. Clark (Engineers) Ltd [1969] R.P.C. 41 at 47). However, the detriment to be shown before the government could claim protection was significantly different to that of a private citizen:

The equitable principle [of breach of confidence] has been fashioned to protect the personal, private and proprietary interests of the citizen, not to protect the very different interests of the executive government. It acts, or is supposed to act, not according to standards of private interest, but in the public interest. This is not to say that equity will not protect information in the hands of the government, but it is to say that when equity protects government information it will look at the matter through different spectacles.

It may be a sufficient detriment to the citizen that disclosure of information relating to his affairs will expose his actions to public discussion and criticism. But it can scarcely be a relevant detriment to the government that publication of material concerning its actions will merely expose it to public discussion and criticism. It is unacceptable in our democratic society that there should be a restraint on the publication of information relating to government when the only vice of that information is that it enables the public to discuss, review and criticise government action.

Accordingly, the court will determine the government's claim to confidentiality by reference to the public interest. Unless disclosure is likely to injure the public interest, it will not be protected.

The court will not prevent the publication of information which merely throws light on the past workings of government, even if it be not public property, so long as it does not prejudice the community in other respects. Then disclosure will itself serve the public interest in keeping the community informed and in promoting discussion of public affairs. If, however, it appears that disclosure will be inimical to the public interest because national security, relations with foreign countries, or the ordinary business of government will be prejudiced, disclosure will be restrained. There will be cases in which the conflicting considerations will be finely balanced, where it is difficult to decide whether the public's interest in knowing and in expressing its opinion, outweighs the need to protect confidentiality. 
In relation to the documents in question in that case, Mason $\mathrm{J}$ was not willing to accept that publication would prejudice national security, except perhaps in the limited sense that other countries might be less willing to provide information on a confidential basis (Commonwealth $v$ Fairfax (1980) 147 CLR 39 at 51 citing Coco $v$ A.N. Clark (Engineers) Ltd [1969] R.P.C. 41 at 53). Security classification, particularly in the absence of evidence as to the basis and currency of the classification, was not sufficient to demonstrate the requisite detriment. In any event, any impact on Australia's foreign relations had already substantially occurred due to the early sale of copies of the book to foreign governments. Mason $\mathrm{J}$ therefore established that there must be an identified impact on the public interest before government secrecy would be protected. ${ }^{6}$

Recognition of the public interest in disclosure of government information had been recognised two years earlier in the case of Sankey $v$ Whitlam ((1978) 142 CLR 1). Former Prime Minister Gough Whitlam and members of his cabinet had been accused of a criminal conspiracy relating to their conduct in office, namely the borrowing of $\$ 4$ billion without approval by the states, allegedly on the premise that they misrepresented the loans as being for temporary purposes where that was known not to be the case. As part of committal proceedings, cabinet papers and other official documents were subpoenaed and objections were raised over whether they were protected from disclosure in evidence by 'Crown', or 'public interest', privilege. It had been more or less accepted before this case that 'a certified claim by a minister to a court that the disclosure of documents would be injurious to the public interest would ordinarily be accepted by the court' (McMillan 2000, pp. 26-27). However, in Sankey $v$ Whitlam the various judges of the High Court held that it was for the court to weigh up the competing public interests for and against disclosure in each case, irrespective of whether the claim for privilege was due to the contents of the documents in question or the claim they belonged to a class which in the public interest ought not to be disclosed. As Acting Chief Justice Gibbs suggested:

The fundamental and governing principle is that documents in the class may be withheld from production only when this is necessary in the public interest. In a particular case the court must balance the general desirability that documents of that kind should not be disclosed against the need to produce them in the interests of justice. The court will of course examine the question with especial care, giving full weight to the reasons for preserving the secrecy of documents of this class, but it will not treat all such documents as entitled to the same measure of

6 The role of the court in assessing whether the Australian public interest in publication overrides the interest in preserving government confidentiality was endorsed by the majority of the High Court in AttorneyGeneral (UK) v Heinemann Publishers Australia Pty Ltd ('Spycatcher case') [1988] HCA 25; (1988) 165 CLR 30 at [32]; see also Attorney-General (UK) v Heinemann Publishers Pty Ltd (1987) 10 NSWLR 86. 
protection - the extent of protection required will depend to some extent on the general subject matter with which the documents are concerned. If a strong case has been made out for the production of the documents, and the court concludes that their disclosure would not really be detrimental to the public interest, an order for production will be made (Sankey $v$ Williams (1978) 142 CLR 1 at 43). ${ }^{7}$

The various members of the court recognised that the public interest in withholding documents may have various elements, including protection of national security or relations with foreign governments. Many were sceptical of broad claims that release of documents of a particular class would impede the candour of advice given to ministers or in the formulation of policy (see Sankey $v$ Williams, Gibbs ACJ at 40, Stephen J at 62-3, Mason J at 97). Instead, importance was placed on preserving the basis on which information is provided to government where disclosure to others would impair confidence in the government and its effective working.

Disclosure of Cabinet papers would therefore generally depend on the content and context, recognising the currency of the information and the broader impacts disclosure may have. But the inner deliberations of Cabinet and whoargued-what may be protected where disclosure would undermine the doctrine of joint responsibility essential to Cabinet's institutional integrity (Sankey $v$ Williams Gibbs ACJ at 41-2, Mason J at 97-98). Importantly, anticipating the arguments accepted in Commonwealth $v$ Fairfax, confidentiality of Cabinet meetings was not of itself sufficient to prevent disclosure. Later cases have drawn on this aspect of the case to emphasise that reference to the public interest in disclosure applied even to government holding of private information when that was provided to the government in supposed confidence (McMillan 2000, pp. 27-30). Thus in Jacobsen $v$ Rogers ((1995) 182 CLR 572 at 590) it was stated:

Confidential information of a business character required to be given by a statute which prohibits the disclosure of the information and protects it from production to a court would appear to present a particularly strong case for immunity. Nevertheless, even where the private right to confidentiality is of some magnitude and its preservation is in itself in the public interest, it must be weighed against the public interest in disclosure for the purposes of the investigation and prosecution of the offences in question (Jacobsen v Rogers (1995) 182 CLR 572 at 592 citing Sankey $v$ Whitlam (1978) 142 CLR 1 at 60-62).

7 See also Mason J at 96: 'In determining this question the court, though it will give weight to the Minister's opinion that the documents should not be produced, is entitled to inspect the documents and form its own conclusion upon the question whether the public interest will be better served by production or nonproduction.' 
Together, Sankey $v$ Whitlam and Commonwealth $v$ Fairfax represent a crucial turning point in the legal protection of government secrecy. ${ }^{8}$ However, they represented cases lost by prime ministers and governments who had themselves played instrumental roles in advocating for and introducing FOI legislation. In some ways, Sankey and Fairfax also represented high points in the case against secrecy, with subsequent developments in public interest privilege and government confidentiality continuing to apply the principles and qualifications set out in those cases without apparent attempts to further expand openness in government.

\section{Lack of authority to disclose government information}

While the publishers were successful in restricting claims of government confidentiality in Commonwealth $v$ Fairfax, this was not enough to lift the injunction and allow publication of the book. The case also considered two other claims for protecting government information: breach of the Crimes Act 1914 (Cth) and breach of the Copyright Act 1968 (Cth). The government was successful in continuing the injunction to restrain breach of copyright. Neither the concerns over the public interest that limited breach of confidentiality in government information in openness of government nor acknowledgement that publication, albeit limited, had already taken place, was sufficient to bring the impending publication within the fair dealing defences to copyright infringement. Fair dealing encompasses criticism or review, but that was unlikely to be successfully argued at any subsequent final hearing of the claim due to the lack of consent to the publication of previously unpublished (in the sense of publicly available) documents, and the lack of significant commentary on the government material. Similarly, the fair dealing exception of reporting the news was unlikely to apply to the subject matter of many of the papers; it would be the publishing of the papers that would create, rather than report on, the news in question. Mason $\mathrm{J}$ was prepared to speculate whether the publishing of unpublished works might be considered fair 'as against a government merely because that dealing promotes public knowledge and public discussion of government action' (Commonwealth $v$ Fairfax (1980) 147 CLR 39 at 55). Similarly, Mason J acknowledged that a defence against copyright infringement might exist where publication would protect the community from destruction, damage or harm, but extending this to publication of material which discloses no clear illegality would 'break new ground' (Commonwealth $v$ Fairfax (1980) 147 CLR 39 at 57). An injunction was therefore granted to prevent publication in breach of copyright until the final hearing of the matter.

8 For example, SSCCLA 1979, p. 59 suggested that the judgements in Sankey 'have challenged, or even undermined, many ideas that were previously held (and are reflected in the [Freedom of Information Bill 1978]) about the relationship between government and the courts'. 
Mason J's speculations about extending the exceptions or defences to copyright infringement were not tested in a final hearing. There has been no significant clarification of the position since then, with doubts still remaining over whether the government occupies any special position in relation to unpublished works or public interest defences to infringement (see Collier Constructions Pty Ltd v Foskett Pty Ltd (1990) 19 IPR 44; Stewart, Grifffith and Bannister 2010, [8.51]-[8.520]). Reviews of government ownership and use of copyright have made a number of recommendations calling for limits on that use (see, for example, CLRC 2005), but it remains a matter for individual departments or the approach taken with individual documents (see, for example, Attorney-General's Department 2010). ${ }^{9}$

The other element of the Commonwealth $v$ Fairfax decision was the claims relating to potential breach of the Crimes Act 1914 (Cth). Section 79 of the Crimes Act creates, among other things, offences for communicating, retaining or receiving information with the intention of prejudicing the security or defence of the Commonwealth. Mason $J$ held that this provision was not enforceable through an injunction to supplement the rights of the Commonwealth to enforce copyright or confidentiality (see Commonwealth $v$ Fairfax (1980) 147 CLR 39 at 50). He did not speculate whether the requisite elements of the offence might be made out in the circumstances of that case. ${ }^{10}$

It is also an offence under s. 70 of the Crimes Act, then as now, for Commonwealth officers to publish or communicate any information or documents that come into their knowledge or possession by virtue of being a Commonwealth officer unless they have lawful authority. This is subject to imprisonment for up to two years. Section 70 has been the basis of a number of convictions for disclosure of government information, the most recent that of Allan Kessing for the disclosure to The Australian newspaper of security risks at Sydney airport which had come into his possession as a Commonwealth customs officer (Kessing $v R$ [2008] NSWCCA 310). Reforms to whistleblowing protection at the Commonwealth level have been proposed but, at the time of writing, legislation is yet to be introduced (Brown 2011). ${ }^{11}$

\footnotetext{
9 That statement expresses support for use of a creative commons licence permitting reproduction provided attribution of government ownership is made, but this is not compulsory and is in many cases merely treated as a default position subject to variation as warranted in the circumstances of the individual agreement or document.

10 Section 79 has since been augmented by s.91.1 of the Criminal Code which makes it an offence for a person to communicate information concerning the security or defence of the Commonwealth or another country to a foreign country or organisation with the intention of prejudicing the security or defence of the Commonwealth, or of giving an advantage to another country's security or defence. An article, record or document which is made, obtained, recorded, retained, forged, possessed or otherwise dealt with in contravention of this Part of the Criminal Code is forfeited to the Commonwealth. It is a defence if the information is lawfully publicly available.

11 For a general discussion of the state of whistleblowing in Australia see Brown and Latimer 2011, pp. 137-157. Note that s.16 of the Public Service Act1999 (Cth) now states:
} 
The offence under s.70 of the Crimes Act is complemented by regulations under the Commonwealth Public Service Act 1902 (Cth). Up until 1974, there were strict limitations on the authority of public servants to engage in public comment on matters of administration or information of which they had official knowledge. At the time of Commonwealth $v$ Fairfax the regulations still required that information concerning public business, the contents of official papers or any matter of which an officer has knowledge officially could only be disclosed in the course of a public servants official duties or with express approval. That general restriction continued until 2006 when it was replaced with regulations prohibiting disclosure of information connected with public service employment where it is confidential or 'it is reasonably foreseeable that that disclosure could be prejudicial to the effective working of government, including the formulation of implementation of policies or programs' (Reg 2.1 Public Service Regulations 1999 (Cth)).

Changes to the regulations relating to disclosure of information followed the declaration in Bennett $v$ President, Human Rights and Equal Opportunity Commission ([2003] FCA 1433) that the previous version was unconstitutional. Bennett was dismissed from his job at the Customs Department on grounds relating to his public comment as a union representative on general staffing issues. Finn $\mathrm{J}$ drew on the constitutionally enshrined freedom of political communication that had been developed by the High Court in the early 1990s (see Nationwide News $v$ Wills (1992) 177 CLR 1; Australian Capital Television $v$ Commonwealth (1992) 177 CLR 106). Under that freedom, any law that burdens the freedom of public servants to disseminate information or communicate government and political matters was subject to the test of validity formulated in Lange $v$ Australian Broadcasting Corporation ((1997) 189 CLR 520 at 567):

When a law of a State or federal Parliament or a Territory legislature is alleged to infringe the requirement of freedom of communication imposed by ss 7, 24, 64 or 128 of the Constitution, two questions must be answered before the validity of the law can be determined. First, does the law effectively burden freedom of communication about government or political matters either in its terms, operation or effect. Second, if the law effectively burdens that freedom, is the law reasonably appropriate and adapted to serve a legitimate end the fulfilment of which is compatible with the maintenance of the constitutionally prescribed

A person performing functions in or for an Agency must not victimise, or discriminate against, an APS employee because the APS employee has reported breaches (or alleged breaches) of the Code of Conduct to:

(a) the Commissioner or a person authorised for the purposes of this section by the Commissioner; (b) the Merit Protection Commissioner or a person authorised for the purposes of this section by the Merit Protection Commissioner; or (c) an Agency Head or a person authorised for the purposes of this section by an Agency Head. 
system of representative and responsible government and the procedure prescribed by s 128 for submitting a proposed amendment of the Constitution to the informed decision of the people ...

The first part of this test was described by McHugh J in Levy $v$ Victoria ((1997) 189 CLR 579 at 622; see also John Fairfax Publications Pty Ltd v Attorney-General (NSW) (2000) 181 ALR 694 per Spigelman CJ):

The freedom protected by the Constitution is not, however, a freedom to communicate. It is a freedom from laws that effectively prevent the members of the Australian community from communicating with each other about political and government matters relevant to the system of representative and responsible government provided for by the Constitution. Unlike the Constitution of the United States, our Constitution does not create rights of communication. It gives immunity from the operation of laws that inhibit a right or privilege to communicate political and government matters. But, as Lange shows, that right or privilege must exist under the general law.

The application of that freedom in the context of disclosure of government information requires recognition of the legitimate interests of the government. Finn $J$ recognised that the complexity, and need, of maintaining public confidence, and the diversity of circumstances in which public officials may disclose information, suggested a variety of legitimate interests may need to be accommodated in any regulation of disclosure. Those legitimate interests included possible restrictions on partisan political activity to preserve the impartiality, neutrality and loyalty of its public service, or restrictions to maintain the effective working or efficient operation of government. In the case of regulations preventing disclosure of 'information about public business or anything of which the employee has official knowledge', Finn J stated:

The dimensions of the control it imposes impedes quite unreasonably the possible flow of information to the community - information which, without possibly prejudicing the interests of the Commonwealth, could only serve to enlarge the public's knowledge and understanding of the operation, practices and policies of executive government (Bennett $v$ President, Human Rights and Equal Opportunity Commission [2003] FCA 1433 at [99]).

In invalidating the regulations, Finn J rejected an argument that the regulations relied on the exercise of discretion in granting authority which would be exercised in the same way as determinations to release information under the FOI Act. Finn J considered the reliance on discretion unreasonably compromises the implied freedom of political communication by turning it into a dispensation and 
possibly resulting in at least the appearance of censorship (Bennett $v$ President, Human Rights and Equal Opportunity Commission [2003] FCA 1433 at [103]). Therefore regulations restricting the authority of public servants to disclose information had to reflect a more considered balance between the competing interests at stake.

\section{Administrative law developments}

The case of Commonwealth $v$ Fairfax indicates that although there was growing judicial recognition of the public interest in disclosure of government information there remained considerable legislative restrictions on that disclosure. The operation of the Copyright Act and Crimes Act provided considerable scope to discourage the disclosure of government information by providing ministers and departments with considerable discretion over what information may be publicly released. These restrictions continued to operate after the introduction of the FOI Act, with substantial reform only now being considered (see ALRC 2010).

There were, however, a number of other legislative reforms that preceded the introduction of the FOI that had important implications for openness of government. In 1971, the report of the Commonwealth Administrative Review Committee, or Kerr Committee (CARC 1971), tabled its findings. Appointed under limited terms of reference to update some of the technical or anachronistic elements of review of administrative decisions, the report presented a plan for a 'new administrative law'. Two subsequent committees (Bland Committee 1973; Ellicott Committee 1973) further developed that plan and led to the introduction of three important elements of the current administrative law system. The Administrative Appeals Tribunal Act 1975 (Cth) established the Administrative Appeals Tribunal (AAT) to undertake merits review of a wide range of government decision and the Administrative Review Council to perform an advisory role. The Ombudsman Act 1976 (Cth) established the Ombudsman's Office to handle complaints and investigate concerns over maladministration. The Administrative Decisions (Judicial Review) Act 1977 (Cth) (ADJR Act) was introduced to simplify and extend the jurisdiction of the Federal Court to review the lawfulness of Commonwealth administrative decision. Importantly, however, '[e]ach of those Acts also affirmed the existence of a new legal right, that a person aggrieved by a decision should be entitled upon request to be given a written statement of the reasons for the decision' (McMillan 2000, p. 3, citing Administrative Appeals Tribunal Act 1975 (Cth) s. 28; Ombudsman Act 1976 (Cth) s. 15(2)(e); and Administrative Decisions (Judicial Review) Act 1977 (Cth) s. 13).

The new administrative law package, particularly the ADJR Act, has had a substantial impact in providing an alternative to the common law system of 
judicial review described by the Kerr Report as 'technical and complex and in need of reform, simplification and legislative statement' (CARC 1971, [21]). However, the common law system remains an essential element of Australia's administrative law system. Its constitutional entrenchment has led to increasing recourse to common law judicial review as the limitations of legislative provision of review rights have been exposed (see, for example, Spigelman 2010). Some commentary has suggested that the ADJR Act may even have had a stultifying effect on the continued development of that common law system (Aronson 2005).

An essential element of that common law review - procedural fairness requires that an individual be informed of the basis for any decision which affects them in a direct and immediate way. After the decision in Kioa $v$ West ((1985) 159 CLR 550), any administrative decision which singled out an individual in a way distinct from the community at large had to be accompanied by notice of the case to be met, including any credible, relevant and significant information that may be adverse to the interests of the individual, or be invalid and of no legal effect. The range of interests protected by procedural fairness expanded considerably after Kioa, with commercial and personal interests and even procedural expectations requiring disclosure prior to being affected (see Re Minister for Immigration and Multicultural Affairs; Ex parte Lam (2003) 214 CLR 1). ${ }^{12}$ It meant that even material submitted to the government in confidence may have to be submitted, in substance at least, in the course of making decisions to which it might relate (VEAL $v$ Minister for Immigration and Multicultural and Indigenous Affairs (2005) 225 CLR 88). Procedural fairness has not, however, extended to an obligation to provide reasons in making a decision (Public Service Board (NSW) v Osmond (1986) 159 CLR 656), something that remains subject only to legislative prescription despite the clear benefit in understanding the elements of the decisions made against them (see Cane and McDonald 2008, p. 145, fn 129).

\section{Parliamentary access}

The final frontier of access to government information, however, has been, surprisingly, the ability of Parliament to require the provision of information. Since Sankey $v$ Whitlam it has been maintained that the rights of Parliament to require disclosure is at least as great as the judicial arm of government. In Egan $v$ Willis ((1998) 195 CLR 424) the High Court held that the NSW Legislative Council could hold a Council member in contempt for failing to produce documents as directed. The Court relied on the principle of responsible government, including the responsibility of the government to the upper house of Parliament. The Court stated that:

12 For a general discussion of the expansion of Natural Justice see Cane and McDonald 2008. 
In Australia, s. $75(\mathrm{v})$ of the Constitution and judicial review of administrative action under federal and State law, together with freedom of information legislation, supplement the operation of responsible government in this respect (Egan v Willis (1998) 195 CLR 424 per Gaudron, Gummow and Hayne JJ; see McMillan 2000).

In a continuation of the dispute, the NSW Court of Appeal held in Egan $v$ Chadwick ((1999) 46 NSWLR 563) that, like the Court in Sankey $v$ Whitlam, the Council could determine claims of legal professional or public interest privilege, subject only to constitutional principles such as the maintenance of Cabinet confidentiality.

Numerous questions remain about the role of Parliament and the courts in enforcing parliamentary access to government information. Despite continued criticism by Senate and parliamentary committees over refusals by ministers and their staff to provide information, recourse continues to be political rather than punitive or judicial in nature (McMillan 2000, p. 30).

\section{Conclusions}

This part has attempted to outline the general legal framework affecting access to government information. It has suggested that the legal context in which the FOI Act was introduced was one of increasing judicial recognition of the public interest in disclosure of government information. Limitations on public interest privilege and government confidentiality, together with enhanced procedural fairness rights to participation, significantly limited the ability of government to restrict information from individuals singled out by administrative action. Legislation introduced in the new administrative law reforms of the 1970s also gave individuals considerable scope to have decisions that affected them as individuals reviewed and amended. The introduction of the FOI Act was not the only legal development that contributed to increased access to government information, and any assessment of its impact should be considered in this light.

However, the capacity of the courts to affect change in the conventions of government control of information utilised in the working of government was limited. There was little scope to encourage the capacity of government disclosure to enhance the legitimacy and effectiveness of government regulation, or to enhance the relationship between government and the public generally. That recognition had to come from within government itself. 


\section{Part II: Operation of the Act: In whose public interest?}

In the second Garran Oration - the first having been given by Sir Robert Garran the year earlier - the Prime Minister, Malcolm Fraser, spoke on the theme of responsible government: 'Those who make government policy and control its implementation should be responsible and accountable for the performance of their trust' (Fraser 1978, p. 22). Beyond effective and democratic electoral and parliamentary machinery, responsible government for Fraser had two fundamental requirements:

First, people and Parliament must have the knowledge required to pass judgment on the government. Secondly, the ministers and government must themselves be in control of public policy so that those who the Parliament and people can call to account are indeed those responsible. To the extent that responsibility is diffused beyond that elected government - other than by legislative intent - to that extent is effective, popular control diminished. These two conditions for effective responsibility in government are complementary, but there are also areas where they compete.

The clearest area of competition is the appropriate extent of confidentiality in government. Too much secrecy inhibits people's capacity to judge the government's performance. A complete absence of privacy in our system, where advisers must be capable of advising governments of different political complexions, inhibits the frank and open discussion between ministers and between ministers and officials which is critical to effective government and ministerial control (Fraser 1978, p. 2).

Three years later, these words would be repeated (Hansard, Senator Puplick, Wednesday 8 April 1981, p. 1257) during the second reading speeches for the Freedom of Information Bill 1981 (Cth), an amended version of which would finally become law a year later. The tension between too much and too little secrecy has dogged the FOI Act since before its introduction. Concerns about the effect access will have on the working of government have continued to shape the boundaries of access to information ever since.

Under Fraser's prescription of responsible government, the role of the public servant was to act as the agent of the elected government. This requires a relationship of confidence and impartiality between senior administrators and government, and between public officials and the public. The role of the public service was not just to administer the executive function of government, but also to contribute to the formulation of new policy, and to facilitate public 
consultation both to encourage new ideas and to test the understanding and reaction to proposals developed by government. The recognition of the political nature of some senior public service positions led the Fraser government to reduce the security of tenure of such appointments (Public Service Amendment (First Division Officers) Act 1981 (Cth)), a trend that continued with new managerialism and corporatisation of the government services as the FOI Act matured (see, for example, Kettl 2000, p. 7). It perhaps merely reinforced the perception that the relationship of trust and confidence extended from the public service to the government of the day rather than the public generally.

This part looks at how the structure and interpretation of the FOI Act arguably helped promote a culture of secrecy within government at a time when other legal and social developments were shifting towards greater openness. It examines the role that notions of ministerial responsibility and the relationship between Parliament, ministers and their departments has had on the development and operation of the FOI Act. It begins by setting out the basic elements of FOI legislation and the objections that were raised against its introduction. It then considers the interpretation of various elements of the legislation, in particular the objects clause, the public interest test in the exemption of documents relating to internal deliberations and the impact of conclusive certificates on the role of external review. It concludes that concerns over responsible government, and the role of the public service within that construction, has restricted the development of the FOI Act and its ability to meet its objectives of enhancing the relationship between the government and the public at large.

\section{The Introduction of the Freedom of Information Bill 1978}

Despite its promises on the eve of election (Australian Labor Party 1972; see Terrill 1998, p. 94), the Whitlam government was unable to pass freedom of information legislation. Efforts to release departmental reports met with considerable resistance within the bureaucracy, advice to ministers more so. Whitlam wrote of his government that it had 'devoted many hours of discussion to freedom of information legislation but not sufficient to overcome the resistance of its most senior and respected public service advisors' (Whitlam 1985, p. 621; see Terrill 2000, p. 99). An interdepartmental committee established to draft FOI legislation reported that FOI was 'extremely complex with far reaching implications' (Terrill 2000, p. 106). They offered no justifications in favour of the introduction of FOI legislation and expressed an intention that such legislation merely codifies rather than expands access. The change in government led to the establishment of a second interdepartmental committee. Prior to its report, however, the Royal Commission on Australian Government Administration had included a highly detailed draft bill and explanatory memorandum among its 
appendices and helped spur increased public pressure for reform (RCAGA 1976, 10.7.20). In June 1978, the Freedom of Information Bill 1978 was introduced into Parliament largely based on the second interdepartmental committee report.

The FOI Bill 1978 established many of the most important elements that continue to characterise the FOI Act. The most important of these features relating to access to government documents is set out below. ${ }^{13}$

\section{Right of access}

Under the FOI Act, every person has a legally enforceable right to obtain access to Commonwealth agency documents and official documents of a Minister, other than exempt documents. This was amended in 1991 to make it clear that this right of access was not affected by the reasons for seeking access. ${ }^{14}$ Importantly, access was not dependant on demonstrating any special interest in or need for the document in question.

\section{Application process}

The basic procedure for accessing documents involved requests in writing to the agency or Minister. Agencies were obliged to assist in framing a suitable request and to direct the request to the appropriate agency or minister. There were time limits (originally 60 days but soon reduced to 30 days) on the agency or Minister to make a decision about the request. Access can be either to a copy of the document or being allowed to inspect it. Reasons have to be given if the request for access is refused wholly or in part. Fees for the application, search and retrieval of documents and deciding whether to grant access were set out in regulations.

\section{Exemptions}

Access to a document could only be denied on a ground set out in the legislation. Grounds for denying access included where providing access would 'interfere unreasonably with the operations of the agency or performance by the Minister of [their] functions' (s.13(3) FOI Bill 1978). ${ }^{15}$ However the main grounds for refusing access related to classification as an exempt document. These fell into three main groups (see Creyke and McMillan 2009, p. 1198):

13 For a discussion of the elements of the Act relating to access and correction of personal information and proactive disclosure of information see Parts III and IV of this chapter.

14 Though note that the applicant's reasons may be relevant to being declared vexatious and prevented from making further requests: see John Ford and Child Support Registrar [2007] AATA 1242; 45 AAR 166 affirmed by the Federal Court in Ford $v$ Child Support Registrar [2009] FCA 328.

15 Note that these provisions have undergone numerous revisions. See below under the discussion about document handling processes in Part IV. 
- Exemptions to protect the workings of government — these included interests such as national security, defence, and international relations; Commonwealth-state relations; the national economy; law enforcement and the protection of public safety; and the financial, property and staff management interests of government. It also covered the processes of government including Cabinet deliberations and the internal deliberative processes involved with the functions of an agency or Minister. ${ }^{16}$

- Exemptions to protect third party interests - these included confidential informants; personal affairs of any person; material obtained in confidence; or trade secrets, business, commercial or financial information.

- Exemptions to uphold other recognised legal interests - these included information which other legislation required be kept secret; and documents subject to legal professional privilege. Enactment and subsequent amendment removed exemptions based on 'public interest' privilege and added documents whose disclosure would constitute a contempt of Parliament of a court; certain documents relating to companies and securities legislation; and electoral rolls and related documents.

These exemptions were often subject to further qualification. For example, refusing to disclose Commonwealth financial, property or staff management information required a 'substantial adverse effect' (ss. 39 and 40 FOI Bill 1978). ${ }^{17}$ Importantly, internal working documents were only exempt if the disclosure would be 'contrary to the public interest' and the AAT was restricted under the bill from reviewing that conclusion (see s.37(4) FOI Bill 1978). Some exemptions, such as Cabinet documents, internal working documents or documents relating to security, defence, and foreign affairs, were also further protected by the issue of 'conclusive certificates', which restricted the capacity of the other bodies to call into question the basis of the exemption. The 1978 Bill, for example, prevented the AAT from reviewing the decision to give the certificate or the existence of proper grounds for the giving of the certificate. These provisions were generally amended in the 1982 legislation to restrict the AAT to whether there existed reasonable grounds for the respective claims. Amendments in 1983 gave the Minister, after the tribunal had found that there were no reasonable grounds for the certificate, the option to revoke the certificate or to give notice that the certificate will not be revoked to both the applicant and each house of Parliament (see Freedom of Information Amendment Act 1983 (Cth) which inserted s.58A).

16 Note that subsequent amendments separated out the exemption relating to Commonwealth-State relations (s.33A) and added exemption for documents that might affect the conduct of tests, examinations or audits (s.40) or discloses unfinished research (s.43A). Recent amendments have further consolidated the exemptions. For a recent discussion of how exemptions relating to Commonwealth-state relations, foreign governments and law enforcement might be interpreted by the AAT: see Maksimovic and Commonwealth Director of Public Prosecutions and Anor [2009] AATA 700 (11 September 2009).

17 See further the discussion in Part III below. 
Agencies and the Minister retained discretion to provide access to documents even though they may be exempt. The Act was not intended to prevent or discourage Ministers and agencies from publishing or giving access to documents (including exempt documents) otherwise than as required by this Act, where they can properly do so or are required by law to do so' (s.12 FOI Bill 1978; s.14 FOI Act 1982). There was also provision to redact documents, i.e. to delete parts of the documents that fall within an exemption.

\section{Access to external review}

One of the key elements of the FOI Bill was the provision for external review by the then newly formed Administrative Appeals Tribunal. The tribunal is generally able to engage in merits review of the decision to refuse or defer access, exercising the powers of the decision-maker within the agency or the minister to consider the nature of the documents sought, ${ }^{18}$ the elements of proposed exemptions and the reasons for and against disclosure. The tribunal, unless restricted by a conclusive certificate, is able to exercise all the powers and discretions conferred on the original decision maker, and may affirm, vary or substitute a new decision for that under review or refer the matter back for reconsideration. There is an onus on the agency or Minister to justify their decision to refuse a request for access. Unlike agencies or ministers however, the tribunal cannot grant access to exempt documents. The conclusive certificate described above ultimately restricts the scope of the tribunal's review. Other decisions under the FOI Act, such as imposing or declining to waive charges or correct personal records, are also generally subject to review by the tribunal.

The FOI Bill also made provision for decisions by agencies, but not ministers, to be reviewed internally (s.54 FOI Act 1982). Seeking internal review was necessary before going to the tribunal. There was also recognition of the role the Ombudsman might play in investigating complaints, particularly about delay, and the relationship with tribunal review. The FOI Act 1982 clarified the scope for the Ombudsman to investigate complaints about actions taken by agencies relating to an access request prior to any tribunal hearing being sought (s.57 FOI Act 1982). ${ }^{19}$

\section{Enactment of the Freedom of Information Act 1982: Objections}

It took almost four years after the introduction of the Freedom of Information Bill 1978 (the FOI Bill) before legislative expression of the so-called simple

18 Note that there are restrictions on the capacity of the AAT to access the documents in some circumstances.

19 For further discussion of the proposed role of the Ombudsman see the discussion in Part IV below. 
principles of open government were accepted in the Freedom of Information Act 1982 (Cth). Upon its introduction, the FOI Bill was criticised for its apparent restrictive approach to access to government information. The ability of ministers to issue certificates establishing conclusively the grounds on which access to documents could be denied, the lack of retrospective effect of the act, the breadth of the exemptions and the delays it permitted all seemed to provide the public servants with the ability to control the release of information (Terrill 1998, p. 91). The Senate Standing Committee on Constitutional and Legal Affairs, after an extensive inquiry with over 168 submissions and 129 witnesses, recommended that the legislation be substantially amended in an attempt to provide greater external scrutiny of any denial of access under the Bill. The government substantially rejected these recommendations in making only limited amendments to the Bill. Criticisms of the Bill largely continued. Further amendments to the cct the following year by the then new Australian Labor Party government did little to alleviate the concerns (Freedom of Information Amendment Act 1983 (Cth)).

Opposition to the Bill highlighted several areas of concern, including the resource and administrative burdens of complying with access requests, the protection it affords to suppliers of information to government and how compliance would be monitored or enforced (see SSCLCA 1979, p. 21). ${ }^{20}$ Concern from within the public service, however, focused on the compatibility of FOI legislation with the Westminster system of government in Australia. The Senate Standing Committee on Constitutional and Legal Affairs reported concerns from the highest levels of the public service about the fundamental attack the legislation represented (SSCLCA 1979, p. 34). Access to government information could erode both the collective responsibility of Cabinet and individual responsibility of ministers for the actions of their department. It would distort the political neutrality and hence loyalty and efficiency of the public service, and remove their anonymity. It would, in other words, present scrutiny of the deliberations and discord within government or the executive at the expense of scrutiny of the outcomes achieved.

The Senate Standing Committee presented the impact of freedom of information on responsible government in a different light. Exceptions to the legislation would preserve the confidentiality of Cabinet deliberations, individual views of ministers and the secrecy of advice tendered to Cabinet (SSCLCA 1979, p. 39). The practice of ministerial responsibility for the actions of their department bore little relationship with the theory - indeed, ministerial responsibility may be revitalised as ministers were required to answer for more of the activities and administrative decisions of their departments (SSCLCA 1979, p. 43). No longer would a minister access details going to the proper and efficient working of the

20 For further discussion of these issues see Part III. 
departments under their responsibility at a time of their choosing. While the loyalty of public servants to government, of whatever persuasion, was important, the increasing influence and delegation of authority to the executive means that the public service should be more open to scrutiny and more accountable for its actions, both to Parliament and the public at large (SSCLCA 1979, p. 47-48). The exposure of the views of public servants may well change the nature of the advice provided, but for the better, particularly if it encourages public servants to join in public debate. As the Senate Standing Committee stated:

It is in the interests of ministers themselves to expose the advice of their officials to public scrutiny so as to improve the quality of that advice and ensure that all possible options have been canvassed. Freedom of information legislation can be in the interest of the public servants and government agencies whose processes are opened up to public gaze too, for it will lead to more adequate public recognition of the effectiveness of the public service. Greater exposure of government agencies to scrutiny can be expected in the longer term to result in a reduction in the level of suspicion and distrust surrounding relations between some government and non-government agencies ...

What has happened, in short, is that critics have got things the wrong way around. It is not that freedom of information will change our governmental system; it is rather that our changing governmental system is contributing to pressures for freedom of information legislation. A Freedom of Information Act is indeed one way to make government adaptable, flexible and effective (SSCLCA 1979, p. 26-27).

Of particular concern to the Senate Standing Committee was the ability to seek external review of decisions under the proposed FOI Act. The 'unnecessarily restricted jurisdiction of the Administrative Appeals Tribunal' was seen as a 'major inadequacy' (SSCLCA 1979, p. 286). Any special relationship between Parliament, ministers and public servants would 'only require that some, not all, documents of political significance ... be protected, and it would not follow that ministers, or senior public servants, alone should decide conclusively what documents bear upon that relationship' (SSCLCA 1979, p. 286) The Senate Committee acknowledged the AAT may properly be restricted by conclusive certificates from determining the public interest in disclosing documents relating to defence, national security, international relations and Cabinet and Executive Council documents. However, review of other exemptions should not be limited by the issue of conclusive certificates. As the Senate Committee suggested:

There is no justification for such a system tailored to the convenience of ministers and senior officials in a Freedom of Information Bill that 
purports to be enacted for the benefit of, and to confer rights of access upon, members of the public. This can only confirm the opinion of some critics that the bill is dedicated to preserving the doctrine of executive autocracy (SSCLCA 1979, p. 180).

As mentioned above, the FOI Bill excluded the AAT from reviewing whether disclosure of an internal working document would be contrary to the public interest. The Senate committee had accepted the exemption relating to internal working documents 'reluctantly' (SSCLCA 1979, p. 218) and mainly due to the public interest criterion allowing all relevant interests to be considered and weighed. It was considered 'naïve to expect that a phrase such as "public interest" can be administered properly by public servants, who clearly have an interest in non-disclosure' (SSCLCA 1979, p. 221). The court in Sankey $v$ Whitlam ((1978) 142 CLR 1) had demonstrated its capacity to balance the competing public interests involved, and the courts would be involved with decisions to refuse access through judicial review of the grounds of refusal anyway. Importantly, a neutral tribunal standing outside the system would best allow for the development and change in emphasis that must necessarily occur in such a broad exemption (SSCLCA 1979, p. 223). ${ }^{21}$ It would permit 'a natural growth in the ideas about the way in which government should relate to the community. The public interest in any situation will not require a fixed result. The result would vary from time to time, depending on many factors' (SSCLCA 1979, p. 222).

The Senate committee recommended that the AAT have the power to review whether disclosure of an internal working document would be contrary to the public interest. The government rejected this recommendation, responding that the 'proper place to challenge a decision not to release a document which is judged would substantially impair the proper and effective working of government was parliament' (see Government Response to the recommendations of the Report by the Senate Standing Committee on Constitutional and Legal Affairs on the Freedom of Information Bill, Hansard, 11 September 1980, p. 803). However, there were changes to the FOI Bill that partially met the committee's concerns. The AAT was given the power to review decisions relating to internal working documents, but conclusive certificates could still be issued in relation to such documents that limited review of the public interest to whether there existed reasonable grounds for such a claim. As we shall see below, this has had a considerable impact on limiting the scope for development of public interest grounds for disclosure.

Few of the other substantive recommendations of the Senate Standing Committee were adopted in the revised Freedom of Information Bill 1981 that, after minor

21 This sentiment was repeated in (SSCLCA 1987, [11.17]) 
amendment, was enacted and came into operation in $1982 .{ }^{22}$ There were only a limited number of substantive amendments of the legislation leading up to the most recent amendments. The change in government in 1983 brought with it changes to the FOI Act to provide a greater right to documents created before the enactment of the FOI Act, shift the ability to review decisions back to the AAT as originally intended, particularly in relation to conclusive certificates, and gradually reduce the time limits for compliance from 60 to 30 days (Freedom of Information Amendment Act 1983 (Cth)). In 1986, application and decisionmaking fees were introduced and search and retrieval fees were increased in a move towards greater cost recovery (Freedom of Information Laws Amendment Act 1986 (Cth)). Agency reporting obligations were also increased. In 1988, amendments were made reflecting the introduction of the Privacy Act 1988 (Cth), and in 1991 there was some clarification and simplification of the procedures and operation of the act as well as a widening of the ability to refuse access due to the diversion of agency resources involved (Freedom of Information Amendment Act 1991 (Cth)). Each of these amendments did little to alter the basic structure and operation of the act and if anything they reflect increased resistance to the disclosure of government information. ${ }^{23}$

The importance of the Senate Standing Committee conclusions goes well beyond the amendments to the original bill or legislation. As this chapter will discuss, they have provided the basis for many of the subsequent reviews and calls for substantive reform of the FOI Act. However, with the benefit of hindsight there are perhaps two main concerns that might be suggested. The first is that the Senate Standing Committee made various observations about the changing governmental system but only considered the value or implications of those changes to the extent they suggested a basis for greater openness in government. They fail to engage with the extent passage of the FOI Act might itself encourage further change and the implications that may have. Secondly, they are based on the assumption that the implementation of the FOI Act will accord with the committee's expectations, which in turn relies on the acceptance by those implementing the act of the value of greater openness in government that underpin those expectations. In other words, the positive impacts of the FOI Act which underpinned the committee's conclusions depend on how the FOI Act is interpreted and implemented. As we shall see in the following discussion, the practical operation of the FOI Act suggests that the concerns of public servants about the effects of the FOI Act may not have been so easily displaced.

22 Perhaps the most important not already discussed was the inclusion of the ability to amend personal records which is discussed below in Part III.

23 For a general discussion of the various amendments to the FOI Act see Paterson 2005. 


\section{Interpretation and operation of the FOl Act: The public interest in disclosure}

One recommendation of the Senate Standing Committee was the inclusion of an objects clause in the FOI Act. As discussed above, the object of the FOI Act was described as extending as far as possible the right of the Australian community to access information in the possession of the government (FOI Act s.3(1)). ${ }^{24}$ It also attempted to encourage a pro-disclosure 'leaning' of the act, so that interpretation of its provisions or exercise of the discretions it conferred was further that object and encourage disclosure (FOI Act s.3(2)). However, despite that explicit intention, any 'leaning' had limited effect (see Bayne and Robinson 1995, p. 114). Early decisions interpreting the provisions of the act cautioned against constructing provisions providing access generously while taking a narrow construction of exemptions which permitted information to be withheld: 'The rights of access and the exemptions are designed to give a correct balance of the competing public interests involved' (News Corporation Ltd $v$ National Companies and Securities Commission (1984) l FCR 64 at 66 per Bowen CJ and Fisher J). By 1987 Burchett J stated:

... it is too late to regard [the objects clause] as introducing any bias into construction of the exemptions in the Freedom of Information Act. They are as much part of the Act as s11, which confers a right to access expressly subject to them and as a right relating to documents other than those which are exempt (Arnold v Queensland (1987) 73 ALR 607 at 626 per Burchett J; see generally Creyke and McMillan 2009, p. 1212).

It is this literal approach to the balance set out in the FOI Act that is reflected in the reasoning adopted in the influential AAT decision of Re Howard and the Treasurer of the Commonwealth of Australia ((1985) 7 ALD 626; [1985] AATA 100).

John Howard, the then deputy leader of the opposition, lodged an FOI request in July 1984 for documents provided by the Treasury to the Australian Council of Trade Unions (ACTU) Task Force during the bargaining over the 1984-85 Budget as part of the accord agreement reached between the Australian Labor Party and ACTU with respect to matters of economic policy. The Treasurer, Paul Keating, issued a conclusive certificate certifying that there were documents that met that request that were exempt as internal working documents, i.e. they 'would disclose matter ... relating to ... the deliberative processes involved in the functions of an agency or Minister or the Government of the Commonwealth' (s.36(1)(a) FOI Act). The issue of the certificate meant that the AAT was restricted to whether there 'exist reasonable grounds for the claim that the disclosure of the document would be contrary to the public interest' (s.58(5) FOI Act).

24 FOI Act s.3(1). 
President Davies of the AAT referred to various decisions restricting the ambit of internal working documents. The ordinary meaning of deliberation involved the weighing up or evaluation of the competing arguments or considerations that may have a bearing upon the exercise of the agency's functions. The exemption does not include purely factual material (s.36(5) FOI Act), reports of scientific or technical experts (s.36(6)(a)), statements of reasons for adjudicative decisions (s.36(6)(c)) or documents that have to be disclosed before a decision is made prejudicial to an individual's interest (s.36(2)), but might include the collection and exchange of facts involved in providing advice, opinion or recommendation. There was also no need for the material to relate to policy formation or be considered as part of the ultimate policy decisions of government (see Re Howard, [8]-[15]).

In considering when the public interest would prevent disclosure, previous tribunal decisions had relied on 'public interest' privilege case including Sankey $v$ Whitlam in concluding that the exemptions for internal working documents protected the integrity and viability of the decision-making process within government. They are designed to encourage debate within government, protect the public from confusion, maintain the integrity of the decision-making process itself by confirming that officials are judged by what they decide rather than what they considered before making up their minds (Re Howard at [18] citing Re Murtagh and Commissioner of Taxation (1984) 6 ALD 112 at 121-122), and prevent 'ill-informed or captious public or political criticism' by those 'ready to criticise without adequate knowledge of the background and perhaps with some axe to grind' (Re Howard at [19] quoting from Lord Reid in Conway $v$ Rimmer (1968) AC 910 at 952, as approved in Sankey $v$ Whitlam). Therefore, while 'the whole of the circumstances must be examined including any public benefit perceived in the disclosure of the documents sought' (Re Howard, [20]), Davies $\mathrm{J}$ was able to suggest general guides relating to disclosure of internal working documents:

(a) the higher the office of the persons between whom the communications pass and the more sensitive the issues involved in the communication, the more likely it will be that the communication should not be disclosed;

(b) disclosure of communications made in the course of the development and subsequent promulgation of policy tends not to be in the public interest;

(c) disclosure which will inhibit frankness and candour in future pre-decisional communications is likely to be contrary to the public interest;

(d) disclosure, which will lead to confusion and unnecessary debate resulting from disclosure of possibilities considered, tends not to be in the public interest; 
(e) disclosure of documents which do not fairly disclose the reasons for a decision subsequently taken may be unfair to a decision-maker and may prejudice the integrity of the decision-making process (Re Howard, [20]).

The documents sought in Re Howard fell within these guides. Although they related to an agreement which placed the ACTU in a privileged position, Davies $\mathrm{J}$ did not accept that the government in forming a budget could not consult on a confidential basis with individual organisations. There were therefore no particular circumstances that favour disclosure (Re Howard, [24][27]). Falling within the guides set out by Davies J was therefore sufficient to shift the persuasive burden to establishing a separate reason for disclosure that offset the impact of disclosing internal working documents of this nature.

The guides set out by Davies J have been subject to considerable criticism, both academic and in decisions of the AAT (for example, Re Rae and Minister for State for Aboriginal Affairs (1988) 16 ALD 709; SSCLCA 1987, 11.7-13). They were not intended to be definitive — as Davies J suggested after setting out the guides:

The FOI Act has been in operation since 1 December 1982. As was said in [previous AAT decisions] the Tribunal has not yet received evidence that disclosure under the FOI Act has in fact led to a diminishment in appropriate candour and frankness between officers. As time goes by, experience will be gained of the operation of the Act. The extent to which disclosure of internal working documents is in the public interest will more clearly emerge. Presently, there must often be an element of conjecture in a decision as to the public interest. Weight must be given to the object of the FOI Act (Re Howard, [21]).

However, the emphasis on the public interest in non-disclosure, expressed in general and non-tangible terms, has arguably enabled reliance on the guides to excuse non-disclosure at the expense of demonstrating actual harm. The criteria suggest the possibility of class exemptions without regard to the content of the documents subject to the disclosure request and the injury to the public interest likely to result from their release. Protection of policy documents would seem contrary to the objects of the Act, protecting the public from confusion and unnecessary debate seems 'elitist and paternalistic' (Eccleston and Department of Family Services and Aboriginal and Islander Affairs (1993) I QAR 60 at 137 per F N Albeitz (Information Commissioner); see Creyke and McMillan 2009, pp. 12211224). The impact on candour and frankness in particular has been rejected by more recent AAT decisions that have emphasised the need for concrete evidence of how the release of the documents would impair the efficient and effective performance of government functions (for example, Re Cleary and Dept of the Treasury (1993) 31 ALD 214; McKinnon and Secretary, Department of Prime Minister and Cabinet [2007] AATA 1969). 
However, the Re Howard criteria continued to be adopted and adapted by decision-makers in refusing access. In 2002, Mr McKinnon, the FOI Editor of The Australian Newspaper, made two FOI requests: for '[r]eports, reviews or evaluations completed in [2002] detailing the extent and impact of bracket creep and its impact on revenue collection of income tax', and '[d] ocuments relating to any review/report or evaluation completed on the First Home [Owners] Scheme ${ }^{25}$ in the last two years' (see McKinnon v Secretary, Department of Treasury (2006) 228 CLR 423 at [30]-[31] per Hayne J). Access to most of the documents that fell within these requests was denied on grounds that clearly echoed many of the criteria adopted in Re Howard. They included: 'Officers of the Government should be able to communicate directly, freely and confidentially', and 'in written form what they would otherwise do orally, in circumstances where any oral communications would remain confidential'; '[t]he release of material would tend to be misleading or confusing in view of its provisional nature'; 'cannot be put into context because of the absence of any explanation of the variables used or assumptions relied on'; not 'fairly disclose the final position reached'; and use 'technical terms and jargon' without 'sufficient information for an uninformed audience to interpret them correctly and reasonably' (quoted in McKinnon $v$ Secretary, Department of Treasury (2006) 228 CLR 423 at [34] per Hayne J).

Each of these public interest grounds was accepted as reasonably open by the original AAT decision in McKinnon of President Downes J. The High Court did not have to explicitly consider the public interest grounds relied on by the government, but all the judgements emphasised the contestable normative assessment involved in determining where the public interest might lie in relation to any particular document. The joint judgement of Callinan and Heydon JJ suggested that ongoing sensitivity, the difficulty of placing information into context, and lack of trust in the public to understand the technicalities and jargon used, or concern over a lack of balance in the way the documents would be reported were not in themselves likely to be reasonable grounds on which the public interest of non-disclosure would be justified. However, jeopardy to candour and desirability of written communications, the tentativeness of matters and recommendations yet to be settled which might mislead the public, ${ }^{26}$

25 A scheme subsidising the purchase of a first home regardless of income.

26 See also:

The release of the material would tend to be misleading or confusing in view of its provisional nature, as it may be taken wrongly to represent a final position (which it was not intended to do) and ultimately may not have been used or have been overtaken by subsequent events or further drafts (McKinnon at 228 CLR 423 at 450 [80] per Callinan and Heydon JJ)

Hayne J also suggests:

In the case of those particular documents, the relevant grounds for the claim were grounds asserting that release of the material shown in the documents had 'the potential to lead to confusion and to mislead the public'. The appellant did not assert that this could not constitute a reasonable ground for the claim that had been made (McKinnon at 228 CLR 423 at 448 [70]). 
and the threat to responsible government of revealing documents prepared for responding to questions in Parliament were all considered possibly reasonable justifications for non-disclosure (McKinnon 228 CLR 423 at 446-447).

\section{Conclusive certificates}

The issue to be decided in McKinnon involved the role of the AAT in reviewing non-disclosure decisions where a conclusive certificate has been issued. In such a case the AAT is not tasked with determining whether disclosure of the documents in question would be contrary to the public interest, but only with whether the documents come within the description of the exemption (for example, are indeed 'internal working documents') and, if so, 'whether there exist reasonable grounds for the claim that the disclosure of the document would be contrary to the public interest' (s.58(5) FOI Act). In the decision of the Full Court of the Federal Court leading to the High Court Appeal, the majority had rejected an argument about whether assessing reasonableness required considering factors both in favour of and against disclosure. For example, Tamberlin $\mathrm{J}$ had suggested that if there is a ground that is not irrational, absurd or ridiculous for a claim that the [desirability of preserving intra-government communications prior to making a decision] ... would not be served by disclosure, then that alone is sufficient' (see the description of the Full Federal Court decision in McKinnon (2006) 228 CLR 423; at 432 [14] per Gleeson and Kirby J; 443 [54] per Hayne J; and 468 [131] per Callinan and Heydon JJ).

The minority of Gleeson CJ and Kirby J held that the approach of the Full Federal Court was wrong in law. The reasonableness of any ground can't be based only on the existence of a relevant consideration in favour of non-disclosure. It must be based on all relevant considerations that have a rational bearing on the claim (McKinnon (2006) 228 CLR 423 at 430-431 [12]). Callinan and Heydon JJ, by contrast, focused on the wording of the FOI Act rather than the correctness of the Full Federal Court's approach. They held that the AAT's role did not involve any balancing exercise between competing reasons. One reasonable ground for the claim disclosure, they continued, is if it is contrary to the public interest, even if there are other grounds going the other way (McKinnon (2006) 228 CLR 423 at 468 [131]). Hayne J agreed with the orders of Callinan and Heydon JJ, but he took a slightly different approach. He stated that 'the tribunal's task is to decide whether the conclusion expressed in the certificate (that disclosure of particular documents would be contrary to the public interest) can be supported by logical arguments which, taken together, are reasonably open to be adopted and which, if adopted, would support the conclusion expressed in the certificate' (McKinnon (2006) 228 CLR 423 at 444 [56]-[57]). 
The difficulty confronted by the court and by the AAT in determining its role in the presence of conclusive certificates comes arguably from the conflation of possibly distinct tasks. A claim that disclosure of a document would harm the public interest in the candour of policy advice, for example, requires an assessment of whether that is a reasonable claim in relation to the particular document in question which requires considering the probative evidence on whether release of that document would have the harm identified; whether the harm identified does indeed go to the broader public interest recognised by the FOI Act rather than the interests of any other individuals or institutions; and how the effect on the public interest of denying release of the document compares to the impacts on the public interest if the document was released. It is arguable that all judges in McKinnon recognised the need to evaluate evidence both in favour and against the impact on the public interest identified by the Minister; it is not enough for the AAT to merely consider whether there are arguments in favour of withholding disclosure being in the public interest. However, the role of the AAT is not asked its view on where the public interest might lie but merely whether there are reasonable grounds to accept the judgement of the minister in relation to each of the distinct elements of that question.

This commonality between the various judgements in McKinnon was accepted in the AAT decision of McKinnon and Secretary, Department of Prime Minister and Cabinet ([2007] AATA 1969). Once again the FOI Editor from The Australian newspaper faced a conclusive certificate refusing access to internal working documents, this time in relation to documents held by the Department of Prime Minister and Cabinet relating to options that had been considered for industrial reform in the previous 12 months or that related to particular consequences of industrial relations reform. Deputy President Forgie rejected various grounds for the conclusive certificate because either the documents in question did not relate to what might be a reasonable ground or that there was a lack of evidence that the particular documents would contribute to the harm identified. ${ }^{27}$ There wasn't a sufficient link made between the need for an apolitical public service and the confidentiality of high level policy advice. As Forgie D.P. suggested, '[w]hy is it that the APS can only behave as a professional and apolitical body if its work in giving high level advice is kept out of the public arena?' (McKinnon (2007) AATA 1969 at [160]) . There was no reasonable basis for concluding that the advice of senior officials would be confused for final decisions taken by the

27 Various documents were also identified as Cabinet in confidence and claimed as exempt under s.34 as documents submitted to or part of the deliberative processes of Cabinet. Forgie D.P. held that while there are 'reasonable grounds for concluding that disclosure of documents in the nature of Cabinet documents ... protected from disclosure under the FOI Act by s.34 would be contrary to the public interest [the documents in question] are not of that nature. The evidence does not support a finding that their disclosure would compromise the confidentiality of Cabinet deliberations and so the notion of collective responsibility of Cabinet' (McKinnon (2007) AATA 1969 at [152]). 
government, or that the public would conclude that decisions were taken on the basis of the incomplete information set out in individual documents (McKinnon (2007) AATA 1969 at [157]-[158]).

Forgie D.P. also rejected as unreasonable the claims that disclosure would impair the frankness of advice, encourage oral rather than written advice which would impair understanding and assimilation of relevant material, and restrict accurate written records of decision-making processes. She pointed to the provisions of the Public Service Act 1999, written directions by the AAPS commissioner provided under that Act and various other materials that set out requirements for written records to be kept. As she suggested:

The APS must ensure that it has reporting arrangements in place to give account of each agency's performance and its effective, efficient and ethical use of resources. That must be underpinned by existence and maintenance of good recordkeeping systems. These are not simply standards to aspire but statutory requirements framed in terms of the APS Values and the Directions made under them (McKinnon (2007) AATA 1969 at [162]).

However, Forgie D.P. accepted that the disclosure of tentative options put forward during the development of policy options might reasonably not be in the public interest. As he put it, various grounds in the conclusive certificates were based on the claims that the government of the day is accountable to the Australian community for what its policy is in a particular area and for what it has included in a particular Bill submitted to Parliament. It is not in the public interest to require it to explain what it considered and what it rejected' (McKinnon (2007) AATA 1969 at [153]).

There may be various arguments about why disclosure of the options considered and rejected, whether the views of interest groups or ministerial advisors or APS officers were preferred and the quality of the advice given might all appropriately be the subject of public scrutiny. However, the limited role of the AAT was to consider the reasonableness of the ground in the then current circumstances.

Those circumstances are that matters relating to workplace relations law are very topical and the subject of much debate. It is not, however, in the interests of the efficient use of resources that a government should be required to disclose options and opinions to which it had, or might have had, regard in formulating its final position. The public's scrutiny of a government policy or of a particular piece of legislation is not advanced by the government's explanation of why it did or did not adopt a particular option: 
The government is currently accountable in the context of the workplace relations for its acts and omissions regarding the workplace relations law that has been enacted and not for amendments to that law that it may enact in the future (McKinnon (2007) AATA 1969 at [155]-[156]).

The two McKinnon decisions made clear that the role of the AAT in reviewing the issue of conclusive certificates did not extend to substituting its view of the impact of the public interest of withholding disclosure. It was a reasonable argument that withholding direct access to the deliberative process could be justified due to the accountability provided by public exposure of the results of that deliberative process and the possible detriment to its candour and efficiency. Thus the public interest protected under the FOI Act was able to be restricted by a view that the benefits of direct access to the deliberative process were outweighed by its costs. It was subject to the view of the Minister as to impact of disclosure on the particular policy in question, rather than the broader impact on policy-making, or government, in general.

\section{Reform}

In its 1987 report on the 'Operation and Administration of the Freedom of Information Legislation', the Senate Standing Committee on Legal and Constitutional Affairs concluded that many of the concerns that had been raised about the protection and promotion of frank policy advice and criticism had been unfounded. They did, however, express concern at the guides set out in Re Howard and their adoption in subsequent cases. In particular, they stated:

The Committee acknowledges that documents relating to policy proposals considered but not adopted can be used to attempt to confuse and mislead the public. But the Committee considers that such attempts, if made, will be exposed. The process of doing so will lead to a better public understanding of the policy formation process (SSCLCA 1987, p. 168).

The 'Open Government' review by the Australian Law Reform Commission(ALRC) and Administrative Review Council (ARC) also emphasised the changing nature of the public interest and how it depended upon the application of amorphous, subjective criteria to the circumstances of each situation (ALRC, ARC 1995, pp. 95-96 at [8.13]). They recommended that the public interest not be defined, but that it should be made clear that factors such as embarrassment to government should be irrelevant (ALRC, ARC 1995, Recommendation 37 at 96). However, it has only been in the recent amendments to the act that these recommendations have been accepted. The most recent reforms to the FOI Act have picked up on this in leaving the public interest undefined, but setting out irrelevant factors as well as factors favouring access. Whether access to the document could result in embarrassment to the Commonwealth government or cause loss of confidence 
in the Commonwealth government; access to the document could result in a person misinterpreting or misunderstanding the document; the author of the document is of high seniority in the agency to which the request for access to the document was made; or access to the document could result in confusion or unnecessary debate can no longer be used as in determining the public interest in withholding a document from release (s.11B FOI Act).$^{28}$ The result of these amendments is that many of the Re Howard factors are no longer relevant when considering the public interest served by withholding a document from release. ${ }^{29}$

The concerns over conclusive certificates have also been the subject of various calls for reform. The 1987 Senate Standing Committee report recommended retaining conclusive certificates. This was based on what they considered the restrained use of such certificates and the accountability of ministers to Parliament if they decline to abide by a decision of the AAT. The Senate Standing Committee, referring only to the use of certificates to that point, suggested that placing greater review powers with the AAT risked undermining ministerial responsibility (SSCLCA 1987, p. 147).

The Senate Standing Committee did recommend, however, the addition of requirements to inform Parliament of the issue of conclusive certificates. There has never been any requirement under the FOI Act to disclose publicly the numbers of conclusive certificates issued. Despite this, the Senate Standing Committee was able to report that there had been 'only' 55 conclusive certificates issued between 1 December 1982 and 30 June 1986, 21 of which were issued by Treasury prior to a change in internal procedures (SSCLCA 1987, p. 145). The only other figures available seem to be estimates of between 12 and 14 conclusive certificates issued between 1996 and 2006 (see Costello, Treasurer 2007; Parliamentary Library 2008). The ALRC agreed that the use of conclusive certificates should be disclosed, but went further in recommending that they be only for a limited duration and calling for the abolition of conclusive certificates in relation to Commonwealth-state relations and internal working documents (ALRC, ARC 1995, p. 117). Other commentators also called for their abolition. As Rick Snell suggested:

The existence of such certificates leaves the Act exposed to changes in political will and bureaucratic commitment to the principles and

\footnotetext{
28 The 'factors favouring access' are if disclosure of the document would promote the objects of the Act; inform debate on a matter of public importance; promote effective oversight of public expenditure; or allow a person to access his or her own personal information.

29 The recent amendments also make the public interest test more significant by applying it to all of what are termed conditionally exempt documents. The public interest test is therefore applicable to all the categories of exemption except those relating to national security, defence or international relations, Cabinet documents, prejudicing law enforcement or public safety, or to which secrecy provisions apply.
} 
objectives of the legislation ... The current restraint in the use of these certificates is not cause to allow the damaging potential of this mechanism to go unchecked (Snell 2004, p. 9).

The decision of the High Court in McKinnon also highlighted, however, the restricted role of the tribunal and the potential manipulation of the certificate process. The Freedom of Information (Removal of Conclusive Certificates and Other Measures) Act 2009 (Cth) abolished conclusive certificates and replaced them with some procedural protections for what may be considered sensitive material relating to national security, defence or international relations and denying access to documents from seven listed security agencies. ${ }^{30}$

\section{Conclusions}

Recent reforms have continued the gradual development of our understanding of the 'public interest' for the purposes of the FOI Act. Of the five guides set out in Re Howard relating to access to the deliberative process, recent reform has left only two: concern over impeding frankness and candour, and disclosure of documents which do not reveal the reasons for a decision subsequently taken, and even these are judged by reference to the particular documents in question rather than available as a general claim. In many ways this reflects the discussion played out in the courts in decisions like Sankey $v$ Whitlam and Commonwealth $v$ Fairfax in the cases of public interest privilege and government confidentiality. However, the role of responsible government continues to be referenced. Recognition that government accountability is aimed at those responsible for the decisions of government has led to importance being given to the collective responsibility of Cabinet and the ability to protect the role of the public service in the provision of advice. This has allowed concerns over the importance of the role of the public service in influencing policy decisions to encourage restrictions on public disclosure of that role.

As the Senate Standing Committee suggested, there is a need to allow for the continuing development of our understanding of the public interest and the balance to be struck between disclosure and withholding access. However, that development has come slowly, and the concerns over use of conclusive certificates has demonstrated continuing resistance within the public service, at least within some departments at senior levels, over promoting disclosure at the possible expense of the involvement of the department in policy setting. Recent amendments to the FOI Act reflect long-held concerns over the ability of the government to interpret the public interest in disclosure unduly narrowly,

30 These include the Australian Secret Intelligence Service, Australian Security Intelligence Organisation, Inspector-General of Intelligence and Security, Office of National Assessments, Defence Imagery and Geospatial Organisation, Defence Intelligence Organisation, and the Defence Signals Directorate. 
restricting access to politically sensitive documents and eroding insight into the policy development process. However, the amendments still reflect a view that access to government information - particularly relating to the deliberative process - may impede rather than enhance the government policy-making process. The role of the FOI Act in encouraging accountability of that process rather than just its product is still to develop.

\section{Part III: FOI and non-government interests}

On 7 September 2010, Prime Minister Julia Gillard announced that an agreement had been reached with two independents returning the Labor party to government. The process of agreement, she stated, had resulted in 'more openness, transparency and reform in how we conduct our Parliament and the business of government than at any other time in modern Australian politics ... let's draw back the curtains and let the sun shine in' (The Age 2010).

Crucial to that agreement was the Labor Party's commitment to the National Broadband Network (NBN). The NBN, built in partnership with the private sector, will reportedly be the single largest nation-building infrastructure project in Australian history (Prime Minister, Treasurer, Minister for Finance and Minister for Broadband 2009). In April 2009, it was announced that it would be built and operated by NBN Co, a company incorporated under the Corporations Act 2001 (Cth). Initially this company would be a wholly owned Government Business Enterprise (GBE), but it has been established with eventual private ownership in mind. As a GBE it will be subject to various forms of accountability and governance requirements in addition to those applicable to incorporated bodies: it has to release annual statements of intent, keep its shareholder ministers informed of financially significant events, and is subject to review by the Auditor-General for example. But as an incorporated body it would not be subject to many other forms of accountability that apply to the public sector, including the Freedom of Information Act 1982 (Cth). ${ }^{31}$

Two months after the Prime Minister's statements about openness, the Senate was demanding access to various documents relating to NBN Co, including release of its business plan, which had been provided to the government in line with commitments under the Commonwealth Authorities and Companies Act 1997(Cth) (Riley 2010). Under that Act and associated guidelines (Department of Finance and Deregulation 1997), GBEs like NBN Co are generally subject to governance and accountability requirements that echo those in the private sector, except that their reporting and other obligations are generally to the government. In

31 See Crowe and NBN Co Ltd [2011] AICmr 1 (25 January 2011), the first decision of the newly created office of FOI Commissioner, affirming that NBN Co is not an entity that is subject to the FOI Act. 
the case of NBN Co, for example, it is the ministerial shareholders who receive reports and hold management to account. While there is an obligation to publicly release a GBE's statements of intent (see Department of Finance and Deregulation 1997, [2.5]-[2.7]), other important reporting requirements may not be available to public scrutiny. Only documents that relate to the affairs of an agency or department of state are accessible under the FOI Act. Where a GBE is not covered by the FOI Act, not even the actions of government in holding the GBE to account are subject to scrutiny under the FOI Act.

A summary business plan was eventually released as part of a compromise deal with independents to get crucial legislation considered by the Senate, but not until various claims had been made about the importance of maintaining the confidentiality of documents going before Cabinet, and the potential confusion arising from the various options outlined in the plan depending on pending determinations by other government agencies. ${ }^{32}$ However, only a summary rather than full plan was released to address concerns over the commercial sensitivity of information in the complete plan, including commercial-inconfidence material gained from third parties and details about current and upcoming tender processes (Wilson 2010). The complete business plan was released a month later (itnews 2010).

In January the following year, realisation that NBN Co was not subject to the FOI Act was acknowledged by the Prime Minister as 'the ordinary operation of the Freedom of Information Act' (Massola 2011). However, enactment of legislation relating to access arrangements for the $\mathrm{NBN}^{33}$ included amendments to the FOI Act to explicitly bring NBN Co under its scope, but also exempted NBN Co in relation to documents in respect of its commercial activities. ${ }^{34}$ In putting forward the amendments, Greens MP Adam Bandt suggested that the public had a 'legitimate interest' in 'one of the largest sums of public money invested in one of the largest infrastructure projects in our history':

The Greens are not prepared to see the continuation of a long-term trend of gradually corporatising government services and then claiming information is commercial-in-confidence. That trend has to be rolled

32 In this case the Australian Competition and Consumer Commission on competition concerns with the plan: see Grattan and Yeates 2010.

33 See Telecommunications Legislation Amendment (National Broadband Network Measures-Access Arrangements) Bill 2011 (Cth), which passed both houses on 28 March 2011, but as of 12 April 2011 had not yet received royal assent.

34 Which is further defined as (a) activities carried on by NBN Co on a commercial basis; or (b) activities, carried on by NBN Co, that may reasonably be expected in the foreseeable future to be carried on by NBN Co on a commercial basis (see clauses 121 and 122 of the Telecommunications Legislation Amendment (National Broadband Network Measures-Access Arrangements) Bill 2011 (Cth)). 
back and [NBN Co] is the place to start. We also believe that maximum transparency is in fact the best way to build public confidence in the NBN (OpenAustralia 2011).

The opposition, however, did not support the amendment, suggesting that, as a business, all of the activities of NBN Co would be conducted on a commercial basis (OpenAustralia 2011).

As part of the amendment, there was to be a review of the operation of the FOI Act relating to documents of NBN Co within 12 months (National Broadband Network Companies Bill 2011 (Cth) s.100A and s.3). ${ }^{35}$ Assurances were given that the review would consider issues raised in the case of Commonwealth $v$ Fairfax, and whether to "tighten FOI rules to prevent documents being withheld on the basis of "confidentiality" unless it was proven their release would be a "real detriment" to the Government or to NBN Co's commercial operations' (Crozier 2011). ${ }^{36}$

The issues surrounding the application of the FOI Act to companies like NBN Co highlights the role the FOI Act plays in the relationship between government and other organisations and individuals. This section will describe the range of agencies and other entities subject to the FOI Act. It will consider how individual interests, of both a commercial and private nature, are protected under the FOI Act and how the FOI Act continues to rely on the distinction between public and private interests despite their interdependence in the development and implementation of public policy.

\section{Subject to the FOI Act}

One of the basic functions of the FOI Act is to provide a right of access to nonexempt documents in the possession of an agency or, in some circumstances, ministers. 'Documents' in turn is very broadly defined to include any method of recording information, including electronically (s.4(1) and s.17 FOI Act). There is only limited scope to require the production of information not already recorded and available to the agency. ${ }^{37}$

An 'agency' is defined in the Act as:

- a department of the Australian public service; or

35 The review was announced on 16 April 2012, to be completed by 30 June 2012 (Roxon 2012).

36 Note however that the terms of reference for the review do not include any such reference. See AttorneyGeneral's Department 2012.

37 Note that s.17 of the FOI Act refers to producing documents of discrete records held on computers. This might include running a search term through a database and providing access to the result. The Act deems access to information in this way as a separate document, but it does perhaps involve reducing information not otherwise distinctly available into documentary form. 
- a 'prescribed authority', which includes unincorporated bodies established under legislation for a public purpose and, where declared in the regulation, other bodies established by the government or over which the government is in a position to exercise control.

Incorporated bodies such as NBN Co are therefore not generally subject to the FOI Act unless prescribed in regulations. Official documents of ministers are documents that are or used to be in the Minister's possession, that can be accessed by the Minister, and which relates to the affairs of an agency (s.4(1) FOI Act). Not all documents in the possession of ministers in their official capacity are subject to the FOI Act; documents relating to the activities of non-agencies such as incorporated bodies are not subject to the right of access under the FOI Act.

Agencies may also be excluded from the operation of the FOI Act in respect of some or all of their activities (s.7 and Schedule 2 FOI Act). Thus bodies set out in Part I of Schedule 2 are exempt entirely, ${ }^{38}$ in Part II in relation to specified documents ${ }^{39}$ and in Part III in respect of their commercial activities. ${ }^{40}$ References to commercial activities in Schedule 2 means activities carried on by an agency on a commercial basis, or foreseeably might be carried on in the future on a commercial basis, in competition with private bodies (s.7(3) FOI Act). Broad interpretations by the AAT have meant that a wide range of activities are potentially captured by this exemption. ${ }^{41}$ An agency and Minister is also exempt in relation to documents, or summaries or extracts of such documents, which originated or are received from various named security agencies, or relate to defence intelligence or restricted technology (see ss.7(2A), 7(2B) and 7(2C)).

There is no clear principled basis that has been used in exempting a body or certain of its documents from the operation of the FOI Act. The ALRC and ARC, in its 'Open Government Report', initially proposed repealing the exclusion of bodies entirely on the basis that the exemptions provide sufficient protection (ALRC, ARC 1995, p. 215). They were convinced, however, that alternative

\footnotetext{
38 This currently includes agencies such as Aboriginal Land Councils and Land Trusts, Auditor-General, Australian Government Solicitor and various security and defence agencies. Previously, GBEs such as the Commonwealth Bank (prior to its privatisation) were also listed.

39 This currently includes Australian Broadcasting Corporation, in relation to its program material and its datacasting content; Australian Postal Corporation, in relation to documents in respect of its commercial activities; Medicare Australia, in relation to documents in respect of its commercial activities; Reserve Bank of Australia, in relation to documents in respect of its banking operations (including individual open market operations and foreign exchange dealings) and in respect of exchange control matters; Australian Statistician, in relation to documents containing information collected under the Census and Statistics Act 1905; and Qantas and Telstra were also listed prior to privatisation.

40 This includes body corporates established under the Dairy Produce Act 1986 (Cth), or Primary Industries and Energy Research and Development Act 1989 (Cth).

41 See, for example, Australian Postal Corporation v Johnston [2007] FCA 386, where listings of licensed post offices maintained by Australia Post were held to be exempt from disclosure as included under Schedule 2. See also Bell and Commonwealth Scientific and Research Organisation (CSIRO) [2007] AATA 1569; (2007) 96 ALD 450 for a discussion of the relevant case law.
} 
forms of accountability and the probable exemption of vast majority of their documents justified the exclusion of the security agencies. GBEs, similarly, should not be prescribed authorities and hence excluded from the act if they are 'engaged predominantly in commercial activities in a competitive market' (ALRC, ARC 1995, p. 216). Those not so engaged in a competitive market should be subject to the FOI Act and the general operation of its exemptions without being listed in Schedule 2. The exemption relating to business and commercial affairs should clearly apply to documents that contain information about the competitive commercial activities of agencies (ALRC, ARC 1995, p. 141). ${ }^{42}$ These recommendations were not, however, adopted in the most recent reforms to the FOI Act, and the controversy over the treatment of NBN Co perhaps highlights the continuing need for this issue to be addressed.

\section{The commercialised state}

Concern over the FOI Act's coverage of the commercial activities of government agencies is just one concern over a trend towards greater commercialisation of government activities in general since its introduction in 1982. Renewed emphasis on the efficiency and effectiveness of government was accompanied by a shift to a 'managerialism' or 'new public management' philosophy, emphasising cost-effectiveness, service quality and organisational performance. ${ }^{43}$ Attempts to expose public services to competition, contestability and market-based mechanisms led to increased use of a range of tools including 'deregulation, commercialisation, corporatisation, public sector down sizing, outsourcing of services and privatisation' (Taggart 1997, pp. 1-2). Accompanying this shift has been concern over the applicability and persistence of public sector forms of accountability (Mulgan 2003). Exclusions of public bodies from the ambit of accountability mechanisms like the FOI Act, or limitations on their exposure, have been questioned given the seemingly increasing reliance on private sector forms of governance and contracting as a means of regulation (Parker and Braithwaite 2003, pp. 119-145). As Finn suggests:

The always fuzzy line between public and private has been reconstructed since freedom of information (FoI) legislation first appeared in Australia ... the commercial relations between government, business and the broader community have been fundamentally reshaped (Finn 2003, p. 60).

At a broader level, the emphasis on market mechanisms and privatisation of government services has brought with it recognition of a broad range of

\footnotetext{
42 This has since been accepted by the Courts. See, for example, Secretary, Dept of Workplace Relations \& Small Business $v$ The Staff Development \& Training Centre Pty Ltd [2001] FCA 1375.

43 On the changing philosophies of the Australian public sector see Wilenski 1988. On new public management generally see Hood 1991.
} 
regulatory mechanisms that can help enhance the achievement of public policy goals. A range of methods was available to the government, often in conjunction with the private sector, to help achieve its public policy — or at least political - aims. Creating and influencing markets, transactional regulation through contract or grant, regulation of structural elements like underlying standards, codes or architecture, and a range of informational regulation ranging from requiring disclosure to performance indicators, ratings or education were added to more traditional command and control mechanisms like requiring licences or approval (Freiburg 2010, p. 85). Most provided for an increased role for government in gathering and processing information.

This has meant that a significant proportion of the information generated and held by the reconfigured government is commercial in nature (see Paterson 2004, p. 321). That information can relate to the commercial activities of government itself, to contractual arrangements entered into with private bodies for the delivery of government services, to the activities and governance arrangements of organisations that government has some interest it, or have been provided in the course of some regulatory scheme in which government plays a supervisory or enforcement role. Finally, that information can be provided during the policymaking process, with the submission of commercial information used to influence the policy setting process or to contribute to a finding and recommendation of a government body. ${ }^{44}$ Each of these avenues for the generation and collection of commercial information encompasses an incredibly broad range of circumstances and regulatory or public policy objectives.

Excluding access to commercial information may therefore have a significant impact on the achievement of those objectives. To the extent to which FOI obligations modify market mechanisms they may reduce the competitive benefits to be gained or have other unintended effects. Potential release of commercial information may increase the risks and hence costs associated with doing business with government, or reduce the incentives to be forthcoming in providing information. However, excluding such information from disclosure where it plays an increasingly important role in the way government is conducted may significantly undermine achieving the objectives of the FOI Act. Adequately scrutinising the conditions in and performance under government contracts, the effectiveness of the market design in achieving its regulatory aims, and the influence of regulatory capture or interest group pressures may all depend on access to documents that necessarily include commercial information of a public or private nature.

44 John McMillan has argued that in some ways the availability of access to information has led to nongovernment organisations asserting a right to set the agenda, propose options or veto proposals: McMillan 2002, p. 30. 
The FOI Act attempts to balance these considerations in a number of ways. As discussed above, the FOI Act is focused on agency documents and there are general exclusions available for some bodies because of their commercial nature or documents relating to their commercial activities. There are also a number of specific exemptions relating to commercial affairs available both to government and non-government bodies to prevent release of documents. Under the 'reverse FOI' procedure (see ss.27 and 27A FOI Act), before release of a document containing information concerning a person's or organisation's private or commercial affairs, they must be given an opportunity to make submissions in support of it coming within the personal or business affair exemptions. These submissions must then be considered in deciding whether to grant access to the document, and if access is to be provided, an opportunity must then be given for proceedings to be brought in the AAT arguing that the exemption should apply.

Up until the recent amendments a document could be withheld as exempt in a commercial context if:

- its disclosure was prohibited under other legislation; ${ }^{45}$

- it disclosed trade secrets or information having commercial value that could be diminished if revealed (s.43(1)(a) and (b));

- its disclosure would found an action for breach of confidence (s.45); or

- it disclosed other information about a person's business or professional affairs or an organisation's ${ }^{46}$ commercial or financial affairs which, if disclosed, could unreasonably adversely affect them or 'could reasonably be expected to prejudice the future supply of information to the Commonwealth' (s.43(1)(c)).

These provisions therefore recognise that commercial interests can be implicated in a request for disclosure of information in a number of ways. Disclosure can affect the intrinsic value of the information itself, the commercial activities of the party providing the information, or the relationship between the government and providers of information. The document being requested can also have originated in three arguably distinct situations: disclosure of information to government, either under compulsion or voluntarily; generated by government itself as part of its commercial affairs; or it relates to government contracts and other commercial affairs (see Paterson 2004, pp. 325-329).

The exemptions to disclosure for commercial information involve the same concern with balancing the effect of disclosure on the commercial interests of businesses and organisations (including the government itself) against the public interest in that information being known. Disclosure may undermine the public policy objective sought through the creation or collection of commercial

45 Either legislation specified in Schedule 3 or which expressly applied the FOI Act exemption: s.38.

46 Including government authorities. 
information, including greater efficiency or effectiveness through use of a market mechanism or correction of a market failure. Alternatively, the information disclosed may be sufficiently distinct from the activities of government, placing the party disclosing the information at a competitive disadvantage, or devalue intellectual property rights. As Gurry has suggested, in discussing both commercial and private information provided to government:

By limiting the use which the State may make of this information to the discharge of the function for which it is received, the law assures citizens that their confidences will not be abused for reasons of extraneous political expedience and provides a framework of trust conducive to the candid disclosure necessitated by the relation of the modern State and its citizens (Gurry 1984, p. 18).

However, the protection against disclosure of commercial information is not absolute. Where disclosure would defeat the regulatory objective of a legislative scheme, there can be explicit provision for non-disclosure of the relevant information. Otherwise, information about business or commercial affairs supplied to the government is protected only to the extent disclosure would reasonably affect them or unreasonably jeopardise trust, for example. The reference to reasonableness has allowed incorporation of elements of the public interest, including other factors for and against disclosure, in recognition that merely relating to the commercial affairs of a body is not sufficient in itself to justify withholding the information (ALRC, ARC 1995, [10.31]).

Information of intrinsic value independent of its use by government is separately protected but only if it can be shown that value would be diminished or it otherwise can be considered a trade secret. The AAT has confirmed that the value of information to a private body is treated differently to that held by the government. For example, in Secretary, Dept of Workplace Relations \& Small Business $v$ The Staff Development \& Training Centre Pty Ltd ([2001] FCA 1375) the tribunal emphasised that 'information must have value to the [agency] in respect of those of its activities which can be said to bear a commercial, as opposed to an administrative or governmental character' (Secretary, Dept of Workplace Relations \& Small Business $v$ The Staff Development \& Training Centre Pty Ltd [2001] FCA 1375, [28]), and stated that

there is a distinction between government functions and trading or commercial functions and that that distinction holds true even though government may deliver its governmental functions to interested members of the public in a commercial format, for example, by 'outsourcing' them to private service providers (Secretary, Dept of Workplace Relations \& Small Business $v$ The Staff Development \& Training Centre Pty Ltd [2001] FCA 1375, [26]). 
Information disclosed in confidence to the government is also protected from disclosure under the FOI Act, but only if it would found an action in breach of confidence (s.45 FOI Act). The courts, drawing on Commonwealth $v$ Fairfax, have confirmed that where information is supplied to, as well as generated by government, determining whether there has been a breach of confidence involves a consideration of the public interest in disclosure (see Smith Kline \& French Laboratories (Australia) Ltd $v$ Sec, Dept of Community Services and Health (1991) 28 FCR 291; 20 IPR 643). But the question of whether information provided to government is confidential doesn't just depend on the intention of the private or government party. It will also be affected by how subsequent use or disclosure of the information serves the legitimate interests of the public purpose that underlies the agency's authority (Smith Kline \& French Laboratories (Australia) Ltd $v$ Sec, Dept of Community Services and Health (1991) 28 FCR 291; 20 IPR 643).

\section{Reform of the protection of commercial information}

Despite the various limitations on the exemptions of commercial information from disclosure, the exemptions have been subject to considerable criticism over the extent they may operate to limit scrutiny of the commercial activities of government. Unlike the exemptions dealing with the internal workings of government, these exemptions affect not only the process and deliberations underlining particular public policy choices but also the evaluation of the outcomes of those choices. Protecting the commercial interests of parties dealing with government may prevent scrutiny of the extent to which the public policy objectives have been achieved. The mere fact that information is commercial in nature, or discloses information about the identity or participation of organisations in commercial dealings with the government, should not, in itself, be protected. Similarly, the mere fact that contracts include confidentiality clauses may merely indicate an intention to prevent public scrutiny of the terms of the contract. The exemptions from disclosure may provide the incentive for agencies to use provisions designed to protect third parties to instead protect the terms of the agreement, or government interpretation and enforcement of them, from scrutiny (see Paterson 2004, p. 328). As Frieberg has suggested,

public costs are often unknown or uncalculated, while private costs tend to be regarded as commercially confidential. For a proper evaluation and comparison of costs to take place, both the public and private sectors will need to make their bottom lines, if not their calculations, more transparent. In the absence of valid comparisons, the process of contractualisation will continue to be based on ideology rather than economics (Frieberg 2010). 
Continuing concern over the expenditure of public funds through contractual arrangements involving confidentiality provisions led the Senate to adopt a continuing order requiring government agencies ${ }^{47}$ to list on their websites various details of all contracts with a value over $\$ 100,000$, including whether there are any confidentiality requirements. Agencies have to also provide reasons for the confidentiality. The Commonwealth Auditor-General reports to the Senate each year on the possible inappropriate use of confidentiality provisions in government contracts (Senate Order for Departmental and Agency Contracts; see also Department of Finance and Deregulation n.d.). There has been a significant decline in the reported use of confidentiality provisions, from around 24 per cent to 10 per cent, since the introduction of the order (see ANAO 2003, p. 13). ${ }^{48}$ The Auditor-General recently concluded there remained 'scope for improvement' in agencies understanding and application of the guidelines in order to assess whether particular contract provisions should be confidential (ANAO 2003, p. 13).

The recent amendments to the FOI Act have, however, sought to extend access to documents relating to the performance of government contracts. In so doing, the amendments have largely adopted recommendations in the 1995 'Open Government Report' (ALRC, ARC 1995, [15.8]-[15.15]) ${ }^{49}$ and the ARC report on 'The Contracting Out of Government Services' (Administrative Review Council 1998). The amendments allow requests for access to documents held by nongovernment parties who provide services under a contract. The services have to be in connection with that agency's functions or powers, and not merely provide services to the agency in question. Agencies are required to include provisions in the contracts to ensure they will be provided with documents held by the contracted service providers upon request from the agency after the agency receives an FOI request (s.6C FOI Act). An agency may not disclose the document under the FOI request if an exemption applies, or if all reasonable steps have been taken to obtain the document under the contractual provisions but the document has not been provided to the agency (s.24A FOI Act). This new amendment reflects what might be considered good practice in respect of monitoring the performance of contracted obligations. It emphasises that the agency retains responsibility for supervision of the contract, and that any

47 Defined as an agency within the meaning of the Financial Management and Accountability Act 1997 (Cth) - generally bodies that owe direct financial reporting and accountability requirements as part of the Commonwealth government.

48 In 2009 there were 41,937 contracts for goods and services totalling \$165 billion. Of these, 4,084 contracts were reported as containing confidentiality provisions. Of the 150 contracts examined, 14 per cent incorrectly included confidentiality provisions and 51 per cent were incorrectly listed as containing confidentiality provisions, thus restricting their access by the Senate and public.

49 The proposal is tied to recommendation 99 of the 'Open Government Report', which was concerned with 'the trend towards government contracting with private sector bodies to provide services to the community' on the basis that it 'poses a potential threat to the government accountability and openness'. 
request for documents is done within the contractual framework. It means, however, that documents cannot be obtained from non-government parties outside of the contractual context.

The recent amendments also clarified how the public interest test applied to those exemptions dealing with commercial concerns. Trade secrets and other valuable information and information provided in confidence remain unconditionally exempt, but documents disclosing business or commercial affairs that might reasonably adversely affect those affairs or prejudice the future supply of information to the government must be disclosed unless their disclosure is contrary to the public interest (ss.47G and 11A FOI Act). While the impact of these clarifications is still uncertain, it may be relevant that some of the cases referred to in Part II, concerning exemptions relating to internal working documents, placed less importance on the public interest in accessing submissions and other documents relating to consultation with non-government organisations. For example, in McKinnon and Secretary, Department of Prime Minister and Cabinet ([2007] AATA 1969) it was suggested by Forgie D.P.:

Those consulting with government are not subject to the same statutory standards as those working within the [Australian Public Service relating to record keeping]. It may be that, in particular circumstances, their candour and frankness would be inhibited. Deliberations and consultations that occur as part of the decision-making process are a different matter and are, in my view, more properly considered in the context of separating the pre-decisional deliberations from the postdecision deliberations and the principle that government is accountable for what is has done, or has omitted to do, in implementing a particular policy but is not accountable for what was put to it or considered by it and rejected (McKinnon and Secretary, Department of Prime Minister and Cabinet [2007] AATA 1969, [174]).

It may be that the courts will continue to allow withholding of documentation involving commercial information received from non-government parties. Therefore the recent amendments enhance the focus of the FOI Act on subjecting the performance of government to scrutiny but they also retain considerable scope for the government to enter into and maintain contractual and other commercial operations largely exempt from such scrutiny.

\section{Private information}

In 1991, the objects clause in the FOI Act was amended to include 'creating a right to bring about the amendment of records containing personal information that is incomplete, incorrect, out of date or misleading' (s.3(1)(c) FOI Act). It was inserted on the recommendation of the Senate Standing Committee on Legal and 
Constitutional Affairs 1987 report on the Freedom of Information Act (SSCLCA 1987, pp. 35-36). Its inclusion is a compromise to address the perceived divergence between the general objects of the FOI Act and the provisions of Part V of the Act, which provided for a general right to amend records relating to an individual's personal affairs. The Senate Standing Committee actually recommended that Part $\mathrm{V}$ be removed from the FOI Act and placed in legislation dealing directly with privacy concerns. The Privacy Act 1988 (Cth) was enacted in the year following the Senate Standing Committee's report, regulating the collection, storage, security, access, correction, use and disclosure of personal information. It required government agencies take reasonable steps to ensure that personal information records are correct, relevant, up to date, complete and not misleading. Access and amendment of personal information remains a part of the FOI Act, however. ${ }^{50}$

Amendment of personal records in Part V was originally included in the FOI Act 1982 only after a Senate amendment was accepted (Hansard (Senate) 8 April 1981, p. 1239; 29 May 1981, p. 2364; see ALRC, ARC 1995, p. 56). The Senate Standing Committee 1979 report (SSCLCA 1979) had anticipated that access to personal records was likely to be a significant proportion of access requests. In the absence of any legislative protection of privacy the Committee recommended that there should also be an ability to correct personal records where they are inaccurate, out of date, contain irrelevant information or are otherwise misleading (SSCLCA 1979, pp. 264-265). Calls to repeal the provisions after the enactment of the Privacy Act 1988 (Cth) have not been accepted. For example, the ALRC and ARC, in the 1995 'Open Government Report', initially proposed removing the correction provisions from the FOI Act (ALRC, ARC 1995, [5.17]). This would have the advantages of removing the overlap and possible inconsistency between the Privacy and FOI Acts and only having one process for amendment of personal records. However, it was concluded that these did not clearly outweigh the disadvantages of the complexity of dealing with 'mixed' requests for both personal and non-personal information, the replication of procedures and exemptions in the Privacy Act and diversion of the privacy commissioner's resources. Importantly, the ALRC and ARC report accepted that access and amendment of personal information 'are as much matters of government accountability and openness as privacy and should, therefore, remain within the FOI Act' (ALRC, ARC 1995, p. 56).

By providing access and amendment of personal records the FOI Act provides a mechanism to scrutinise not only the accuracy of those records, but also the process and systems developed to collect and use the information in question. It helps to ensure that the design of those systems accord with the intended public policy objectives, and that the benefits outweigh the impact on personal

50 Note, however, that the recent reforms included altering the objects clause to once again remove explicit reference to access and amendment of personal records: see s.3 FOI Act 1982 as amended Act no.139, 2010. 
privacy concerns. It therefore potentially goes beyond the privacy requirements of making only authorised and consented use of personal information, as well as providing a means to scrutinise compliance with other administrative law and FOI Act requirements to disclose the basis on which decisions are made to the detriment of a person's interests, especially when those decisions are made on the basis of considerations personal to an individual. Access to personal records also ensures that record-keeping practices are subject to scrutiny of sort, allowing the FOI Act to augment good record-keeping requirements in other legislation and as implicitly encouraged through FOI access requirements. ${ }^{51}$

Under the FOI Act, a person can request either an amendment or an annotation of records they have lawfully obtained containing their personal information (s.48 FOI Act). The agency has discretion to amend or annotate the record; though to the extent practicable they should not obliterate the previous text of the record (s.50 FOI Act). If the agency declines to amend the record then they must annotate the record with any statement provided by the person who is the subject of the record (s.51A FOI Act). Refusals to amend or annotate, or delays in responding to requests, are generally reviewable by internal and merits review, and now through the Information Commissioner. The amendment provisions have caused some concerns over the ability of applicants to essentially rewrite findings of fact or conclusions as to matters that are subject to disputes in other forums or under other regulatory schemes (see generally Creyke and McMillan 2009, pp. 1200-1201).

The relationship between the FOI Act and privacy concerns are also reflected in the exemptions for disclosure of personal information. Apart from the protection of information disclosed in confidence discussed above, the FOI Act also exempts unreasonable disclosure of personal information about any person (s.47F FOI Act 1982 (as amended Act no.139, 2010), previously s.41). ${ }^{52}$ Again, the reference to reasonableness has been held to incorporate a public interest test (for example, Colakovski $v$ AOTC (1991) 100 ALR 111). The Privacy Act 1988 also provides limitations on the release of personal information to another person, but this is not generally subject to public interest considerations. The recent reform of the FOI Act has made it clear that unreasonable disclosure of personal information involves consideration of the extent the information is publicly known, the person was known to be associated with matters dealt with in the document, and whether there are other public sources of the information. It is also now clear that documents containing personal information are to be released unless that would be contrary to the public interest, so that factors favouring release of

51 See further the discussion in Part IV below.

52 Note there is provision to release information provided by a qualified person (medical practitioner, psychologist, counsellor, etc.) to another qualified person if it appears to the agency or Minister that disclosure might otherwise be detrimental to the applicant's physical or mental health or well-being. 
the documents are also to be considered as well as those favouring withholding access (s.47F, s.11 A and s.11B). Like the commercial information exceptions listed above, the 'reverse FOI' provisions apply to provide a person whose personal information is contained in requested documents and who might reasonably wish to contend that the document is therefore exempt, an opportunity to make submissions or to seek review of any decision to grant access before access is in fact provided (s.27A FOI Act 1982 as amended).

Personal information can include the names and other information of public servants whose duties were associated with requested documents. It was acknowledged in the 'Open Government' review that ' $[t]$ he disclosure of personal information of public servants as it relates to the performance of their duties for the government does not unduly threaten personal privacy and reflects the democratic objectives of FOI' (ALRC, ARC 1995, p. 131, quoting the Privacy Commissioner DP Submission 81). This was, however, subject to situations where harassment or personal security could be threatened or where information related to investigations into conduct affecting fellow public servants. The public interest test has to incorporate these considerations so as to ensure that the traditional anonymity of public servants is removed in favour of subjecting the bureaucracy to scrutiny (ALRC, ARC 1995, p. 131).

Similarly, the identity of persons who have made allegations that another person is involved in some form of wrongdoing may be withheld on a number of grounds, such as law enforcement, adversely affecting the operations of agencies, or breach of confidence as well as personal information. Other administrative law obligations may require the identity or substantial content of the allegations to be disclosed ${ }^{53}$ and the FOI Act doesn't prevent a breach of those obligations resulting in the invalidity of the administrative decision in question.

\section{Conclusions}

The FOI Act attempts to balance the interests of both government and nongovernment organisations, recognising that these are interrelated in the development and institution of policy. However, there has been a concern that the interests of non-government parties are unduly elevated, particularly in the application of exemptions to disclosure. There is too much discretion given to government agencies to either claim confidentiality or seek exemptions to preserve their own interests rather than those of the non-government organisation involved. Dealing with disclosure of non-government information involves balancing difficult and potentially incommensurate factors when identifying

53 For example, obligations of natural justice require disclosure of information which may be credible, relevant and significant to an adverse effect on a person's interests: see VEAL $v$ Minister for Immigration and Multicultural and Indigenous Affairs (2005) 225 CLR 88. 
where the public interest may lie. Separation of the elements of the public interest favouring disclosure from general concerns over the accountability of non-government organisations and their role in public activities remains difficult but crucial to the effective operation of the FOI Act.

\section{Part IV: Developing a culture of disclosure}

Two days before the release of the 1980 federal budget, Journalist Laurie Oakes disclosed details of a draft (see Blenkin 2011) of the budget speech on national television. The source of the 'leaked' draft has never been revealed. It proved highly embarrassing to the then Treasurer, John Howard, and led to the Prime Minister, Malcolm Fraser, declaring that at least his office 'was not going to play that game [of leaking to advance a person or policy], ever' (see Skeketee 2011). So-called 'authorised leaking', however, has become a matter of course, particularly in relation to budget material, with speculation about impending budget measures being selectively released on a confidential basis to journalists in the hope of gauging and affecting public reaction to the official policy. As Laurie Oaks himself, perhaps not surprisingly, suggested many years later, 'leaks, and whistleblowers, are essential to a proper democratic system' (Oakes 2005; see Brown 2007, pp. 19-28). As Sir Humphrey in Yes Minister suggests, '[t]he ship of state ... is the only ship that leaks from the top' (Wikipedia n.d.).

Leaking, or whistleblowing, to an external agency, and particularly to the media, is a relatively extreme demonstration of the independence of the public service or individual members of government. ${ }^{54}$ The extent of that independence to whom the duties of the public service are owed - lies at the heart of the role of FOI in enhancing government policy development. Peter Shergold, then Secretary to the Department of Prime Minister and Cabinet, expressed it in this way:

Of course the Australian Public Service needs to be accountable for the way it plays its role. It is - more than ever before. The Westminster tradition has evolved considerably in the last thirty years: there is now much greater scrutiny of public service decision-making than in the past through Parliamentary committees, the Audit Office, and the Ombudsman; through legislation which, within limits set by Parliament, provides freedom of information to the public; and the opportunity, through an extended panoply of administrative law, for citizens to have decisions reviewed. There is now a network of integrity which did not exist 30 years ago.

54 For a discussion of whistleblowing in the Australian context see Brown 2008. 
Yet confidentiality remains a fundamental requisite of democratic decision-making. A public service that cannot provide its frank advice in confidence will rapidly lose its ability to influence. No government will willingly involve officials in decision-making if they fear that the written advice, or an account of its oral discussion, will end up in the newspapers if the government's judgment is not accepted. Those who leak the deliberations of government (as opposed to those who whistleblow on corruption), undermine democratic process. They erode the trust between government and public administration that lies at the heart of good governance. They diminish the opportunity for public servants to inform and influence policy and, conversely, reduce the willingness of government to seek the broadest range of advice from across the administration. They undermine whole of government approaches. It is for that reason that I protect the confidentiality of ministerial decisionmaking just as zealously as journalists protect the confidentiality of their informants (Shergold 2006).

But there are concerns over the public service acting merely as agents for the government. In 2006, Andrew Podger, reflecting on his 37 years in the public service, including his roles as Secretary of the Department of Health and Ageing, and Public Service Commissioner, criticised what he termed the overly responsive nature of some elements of the public service. As he suggested then, greater emphasis should be given to the public services 'obligations of professionalism, impartiality, being apolitical and complying at all times with the law: the obligations that imply a degree of independence notwithstanding our need to be responsive' (see Grattan 2005).

Podger was particularly concerned at the public service's role in an incident in the lead up to the 2001 general election where it was alleged that children of asylum seekers were being deliberately thrown into the water to enhance their chances of being allowed to enter Australia. The subsequent 'Senate Select Committee for an Inquiry into a Certain Maritime Incident' reported that the minister involved, Peter Reith, made 'a number of misleading statements, implying that the published photographs and a video supported the original report that children had been thrown overboard well after he had received definitive advice to the contrary' (SSCICMI 2002, p. xxiv).

The Senate Select Committee summarised their conclusions by pointing to a number of factors that contributed to the false reports, including 'genuine miscommunication or misunderstanding, inattention ... and deliberate deception motivated by political expedience' (SSCICMI 2002, p. xxii). But also important 'was avoidance of responsibility, a public service culture of responsiveness and perhaps over-responsiveness to the political needs of ministers' (SSCICMI 2002, p. xxii). This and other instances of over-responsiveness suggested that 
'some senior public servants are too concerned to please and serve partisan government interests by failing to keep proper notes, destroying diaries and ratcheting up security classification of documents' (Public Service Informant, July 2005, as quoted by Timmins 2006).

The different views about the role of the public service reflect continuing appreciation of the importance of the relationships between government and the public in the development and implementation of public policy. So-called 'authorised leaking of proposals' to assist with formal delivery recognises that engaging with media, stakeholders and the broader community can play an important role in both policy development and delivery. A public service that acts to support the government of the day can play an important role in both reducing political risks but also, ultimately, enhancing the effectiveness of government by greater engagement with the public at large.

In the latest review of Commonwealth administration, 'Ahead of the Game: Blueprint for the reform of Australian government administration', the relationship between ministers and the public service is described as a 'partnership to develop policy and implement government programs and services' (Department of the Prime Minister and Cabinet n.d.). The report sets out a 'vision for the future' including:

An APS that captures ideas and expertise through the transformative effect of technology by:

- Citizens directly communicating their views and expertise to government through multiple channels, including Web 2.0 approaches (for example, online policy forums and blogs);

- Greater disclosure of public sector data and mechanisms to access the data so that citizens can use the data to create helpful information for all, in line with privacy and secrecy principles; and

- Citizens become active participants involved in government, rather than being passive recipients of services and policies (Department of the Prime Minister and Cabinet n.d., p. 38).

This recommendation was complemented by the release of a separate report from a taskforce established to examine the role of technology in facilitating interaction with government. In 'Engaged: Getting on with government 2.0', the taskforce suggested that new collaborative technologies associated with the internet promised 'new tools for public servants to engage and respond to the community' (Government 2.0 Taskforce 2009, p. x). Embracing these possibilities, however, required

[l]eadership, and policy and governance changes ... to shift public sector culture and practice to make government information more accessible 
and usable, make government more consultative, participatory and transparent, build a culture of online innovation within Government, and to promote collaboration across agencies (Government 2.0 Taskforce 2009, p. x).

It requires changing the approach to government information, from a resource for government to 'a national resource that should be managed for public purposes' (Government 2.0 Taskforce 2009, p. x).

Together, these recommendations have been supported by the government through a 'Declaration of Open Government' based on principles of informing, engaging with and participation of the public (Department of Finance and Deregulation 2008). Mirroring developments in the US (http://www.data.gov/) and the UK (http://data.gov.uk/), the government has established a website gateway to accessing government datasets (http://data.gov.au/), and released guides as to the ways in which information is released to encourage access and reuse by the public (Australian Government n.d.). The recommendations are also reflected in recent reform of the FOI Act that now includes among its objects to provide the community with access to information held by the Commonwealth government, an intention 'by these objects, to increase recognition that information held by the Government is to be managed for public purposes, and is a national resource' (s.3(3) FOI Act 1982).

As the other parts of this chapter have suggested, these sentiments are not new. The original principles of the FOI Bill 1978 reflected the same objectives to both provide a right of access but also to encourage the proactive disclosure of government information. But there has been a shift in the nature and function of that information. As the first annual report on the operation of the FOI Act 1982 suggests, the FOI Act 'requires information about the operations of Commonwealth agencies to be made publicly available, particularly rules and practices affecting members of the public in their dealings with those agencies' (Attorney-General's Department 1983). Proactive disclosure of information held and generated by government may extend beyond informing the individual about how decisions about their interests are going to be made to informing the public more broadly.

This section examines the obligations of proactive disclosure in the FOI Act 1982. It looks at the limited nature of that disclosure when compared to developments in administrative law more generally. It then considers the extent to which proactive disclosure has been affected by considerations of resource constraint, including the impact on document handling and retrieval and the ability to recoup costs of FOI obligations, as well as the role of the Ombudsman or other government agencies in encouraging a pro-disclosure culture. It then 
considers the recent introduction of the Office of the Information Commissioner and the important role it will play in both encouraging proactive disclosure and enhancing government information processes more generally.

\section{Publication of certain documents and information}

Part II of the FOI Act, headed 'Publication of certain documents and information', was described by the 1979 Senate Standing Committee as 'one of the least known and publicised parts of the [FOI Bill 1978], but in our view one of the most important' (SSCLCA 1979, p. 87). It provides for:

- the publication of an annual statement of the general organisation and functions of an agency, particularly decision-making powers affecting members of the public; how the public can participate in policy development or administration, what documents are already or customarily made available to the public, how physical access to documents can be obtained and the procedures and contacts for making an FOI application (s.8 FOI Act 1982);

- making available to the public documents which are used by the agency in making decisions that affect rights, privileges or benefits, obligations, penalties or other detriments; including rules, guidelines or practices relating to the administration or enforcement of legislative or executive schemes; and at least once a year compiling a list of such documents (s.9 FOI Act 1982); and states that

- a person can't be prejudiced where a rule, guideline or practice is not made available or listed; provided the person was not otherwise aware of the rule, guideline or practice that should have been available or listed, and they could have avoided being prejudicially affected if they had known about it (s.10 FOI Act 1982).

These sections were the subject of considerable scrutiny during the enactment of the FOI Act. Amendments to the original Bill went beyond the recommendations by the 1979 Senate Standing Committee in some respects, particularly the provision for a lack of prejudice if the required 'hidden law' of the agency was not made publicly available. However, the provisions have never perhaps taken on the importance envisaged by the Senate Standing Committee.

The ALRC and ARC 'Open Government Report' suggested that the main aim of the provisions was to provide the public with guidance about the information held by the government, primarily to assist the formulation of access requests. However, the information disclosed under the provisions 'was not easily accessible and is rarely used' (ALRC, ARC 1995, p. 81). The internet being very 
much in its infancy, ${ }^{55}$ the report recommended access be expanded beyond the regional offices of the Australian Archives to Australian Government Publishing Service shops, public libraries and branches of the relevant agency. Availability of the information needed to be better publicised. Compliance with the provisions was patchy and there was a need to monitor and enforce compliance through establishment of an FOI Commissioner.

Subsequent reviews of the operation of the provisions have confirmed their limited effect. The report by the Australian National Audit Office (ANAO) on 'Administration of Freedom of Information Requests' (ANAO 2003) found that only half of the agencies required to provide details of documents used to make decisions that affect the public in 2002-03 had done so, and only 31 per cent of the lists of such documents was current. There were no processes to actively follow up on lapsed statements (ANAO 2003, p. 40). However, the ANAO recommended that the amendment of the provisions be considered to provide for disclosure through an agency's website. In the 2006 'Scrutinising Government' report, the Ombudsman reached a similar, if not quite as extensive, conclusion about lack of compliance with Part II requirements (Commonwealth Ombudsman 2006, p. 15).

There has also been almost no case law on the interpretation and operation of the provision (see, for example, Duncan v Chief Executive Officer, Centrelink [2008] FCA 56). The few places where access was available, the uncertain definition of the information to be published, and a focus on rules and practices that might have an effect on individual interests all limited awareness of the availability and usefulness of the FOI requirements. Importantly developments in other areas of administrative law, in particular natural justice requirements, generally placed more extensive obligations for disclosure of how decisions affecting individual interests would be made. For example, natural justice obligations do not generally depend upon showing how any prejudice arising from the non-publication of the information may have been avoided. There was also considerable disparity between agencies as to how willing they were to adapt to the publication and information facilities of the internet. Agencies involved with high volume decision-making on an individual level were responding to a number of factors other than FOI requirements to embrace the information provision facilities the internet provides, including the need to reduce costs, remove duplication of services, improve 'client' satisfaction and reduce complaints (ALRC, ARC 1995, [7.7]-[7.8]).

55 The 'Open Government Report' mentions the recent establishment of a server at the National Library that could be used to provide access to government files. 


\section{Recent amendments}

The recent amendments to the FOI Act include extensive reform of Part II. The new Information Publication Scheme (IPS) is intended to transform the FOI framework 'from one that is reactive to individual requests for documents, to one that also relies more heavily on agency driven publication of information' (OAIC n.d.). The IPS requires agencies ${ }^{56}$ to disclose a broader range of information and encourages further proactive, and more accessible, disclosure of government information. An agency must have a plan stating what information it will proactively disclose, and how and to whom it will disclose it. Agencies continue to have an obligation to disclose their structural and organisational details, including decision-making powers affecting members of the public, how the public can comment on policy proposals, and other relevant contact information. Information in documents to which the agency routinely gives access in response to FOI requests or in response to requests from Parliament are also required to be disclosed in the IPS, although not if it is subject to exceptions (s.8C FOI Act) including personal and business information personal to those making an FOI request (see s.8(2)(g)(i), (ii) FOI Act). Information about how decisions affecting individuals are made is now included in a broader 'operational information' category, including all information which assists the agency perform its functions affecting members of the public. ${ }^{57}$ Each agency IPS entry is required to be 'accurate, up-to-date and complete' (s.8B FOI Act).

Agencies are also required to consider the objects of the FOI Act and guidelines issued by the Information Commissioner when complying with IPS requirements (s.9A FOI Act). The Information Commissioner reviews the operation of the IPS, including investigating compliance, either after receiving a complaint or on its own motion (s.8F FOI Act). Results of that review will be provided in the Information Commissioner's annual reports. There are no direct enforcement measures provided, however, with the commissioner having limited compulsory powers in relation to the conduct of the investigation (see sections 79ff). Similar to prior to the amendments, a failure to list 'operational information' on the IPS can't prejudice an individual whose interests are affected by a decision assisted by that information, but only where the prejudicial affect could have been avoided if the information was known (s.10 FOI Act).

\footnotetext{
56 Note the IPS does not apply to ministers and their offices.

57 Section $8 \mathrm{~A}(1)$ FOI Act includes '[t]he agency's rules, guidelines, practices and precedents relating to ... decisions and recommendations'. The Office of the Australian Information Commissioner Guidelines state that operational information does not encompass information including policy analysis; hypothetical discussion; case study and culpability reports; audit and evaluation reports on the operation of a government program; and case management recording procedures (see OAIC n.d., [13.97]). However, such information may be published proactively or when subject to a FOI request.
} 
Agencies are also able to publish other information as part of the IPS (s.8(4) FOI Act) and are of course not precluded by the FOI Act from publishing information generally, including information that could be withheld as exempted from disclosure if the subject of an FOI request (s.3A FOI Act). ${ }^{58}$ The Office of the Australian Information Commissioner (OAIC) guidelines point out that agencies are required to explain in their agency plan the steps they will take to review their information holdings and identify information that may be suitable for publication' (OAIC n.d., [913.107]). They suggest that agencies should have regard to the interests of clients and stakeholders, general community interest, public demand, assistance in dealing with the agency, promotion of agency accountability or public understanding, whether the information is in an appropriate format to be accessible and reusable, ${ }^{59}$ whether it needs revising or updating and whether there are privacy or security concerns (OAIC n.d., [13.109]). The discretion as to what additional information to release and where to release it remains with the agency however.

\section{Disclosure logs}

The recent amendments to the FOI Act also require both agencies and ministers to publicly release information in a disclosure log that has been released in response to an FOI request. Prior to this amendment, the FOI Act did not make explicit provision for the general release of information. Such forms of disclosure have, however, always been available. The exemptions to disclosure in the FOI Act provide a basis to withhold publication, but don't generally prevent disclosure where not otherwise prevented by other legislation or obligations of confidentiality. Release of documents in response to an FOI request has been, in effect, to the world at large, although in practice it was often up to the recipient of the information to release the information more broadly. The new disclosure log requirements formalise this aspect and provide for increased access to the information that has become publicly available.

Agencies and ministers must now publish, on their websites, lists of information released in response to an FOI request for documents held by the agency or Minister and either provide access, direct links or other details on how the information may be obtained (s.11C FOI Act). The information must be published within 10 working days of the grant of access to the FOI applicant. ${ }^{60}$ There have been concerns raised by media organisations that this reduces their incentive

\footnotetext{
58 Note the discussion relating to general secrecy provisions under other legislation and the Public Service Act in Part 1 above.

59 Further reference is given to the publication on www.data.gov.au and the checklist available at www. finance.gov.au/e-government/better-practice-and-collaboration/better-practice-checklists/index.html.

60 There are no specific requirements as to how long the information must remain accessible, but archiving the information or making it available on request would meet the requirements under the FOI Act for access. See (OAIC n.d., [14.42]).
} 
to make requests and pay the resultant fees if the information is going to be released publicly (see, for example, Australia's Right to Know Coalition 2011; Sear 2011). The Information Commissioner has recommended that maintaining trust and cooperation between agencies and FOI applicants, both in respect of particular agencies and the climate of efficient processing of FOI in the future, be considered in deciding how soon to publish released information on disclosure logs. Fees or charges might be waived, particularly where the information is released and published at the same time. The format to be adopted by the disclosure logs are not set out in the legislation, but OAIC guidelines refer to various government policies and standards to help ensure the documents are easy to locate and access (OAIC n.d., [14.50]), including by all members of the public (see the discussion in the guidelines about accessibility standards, OAIC n.d., [14.59]-[14.61]).

Personal, business, commercial, financial, professional affairs or other information of a kind determined by the Information Commissioner can be withheld from inclusion on the disclosure log where that would be 'unreasonable'. Generally this means that the disclosure logs won't include information about persons or businesses that also made the request. Releasing documents including the name of the agency official mentioned in connection with their duties would not be unreasonable. Note that these provisions mean that the decision to list a document on the disclosure log is separate and generally distinct from the decision to release the document. Procedures for informing a person or organisation whose information is included in released information do not apply to listing on disclosure logs, through the OAIC guidelines recommend including information about potential inclusion on disclosure logs in any 'reverse FOI' procedure (OAIC n.d., [14.19]).

\section{Role of the Information Commissioner}

The 1979 Senate Standing Committee review of the FOI Bill 1978, after summarising its recommended changes to the Bill, pointed out that '[l]egislation of course is one thing; its effective operation can be entirely another' (SSCLCA 1979, p. 30). While the committee expressed its hope that agencies would cooperate in the spirit of the legislation, it was 'essential that the operation of freedom of information legislation be kept under constant review' (SSCLCA 1979 , p. 30). There was a need not only in monitoring and review of the operation of the Act and the balance of competing interests it represented, but also in mediating between agencies, individuals and the broader public interest. A body was needed to act as conciliator in disputes between agencies or ministers and individuals, counsel or assist individuals before the AAT in appropriate cases, and, going beyond enforcement of rights and obligations under the Act, to also provide advice and criticism to other departments. 
The Senate Standing Committee recommended that these functions be split. A department directly headed by a Minister directly responsible, and answerable on a regular basis, to Parliament would have 'administrative responsibility for monitoring compliance with [FOI requirements] and of systematically reporting as to the extent to which agencies had fulfilled their obligations' (SSCLCA 1979, p. 305). The Attorney-General's Department was selected for this purpose. The close comparability of the other required functions with the 'general administrative role performed by the Ombudsman', and the resource benefits of not having to establish a separate bureaucracy meant that the Ombudsman's Office was preferred to the establishment of an at least formally separate Information Commissioner (SSCLCA 1979, p. 306). The Senate Committee felt that the powers of the Ombudsman's Office would need to be expanded to ensure that it could adequately fulfil these additional functions under the FOI Act. ${ }^{61}$

Much of this role of the Ombudsman, along with the role of monitor and rapporteur, was realised by enactment of the FOI Act and its 1983 amendments. However, resource constraints in the mid-1980s led to the general monitoring and reporting roles being shifted to the Attorney-General's Department (Freedom of Information Amendment Act 1991 (Cth), based on the recommendations of the Parliament of Australia; SSCLCA 1987). ${ }^{62}$ The Ombudsman's Office was therefore left with its general powers under the Ombudsman Act 1976 (Cth) to investigate administrative actions of government agencies, including FOI matters, either upon compliant or on its own motion. Decisions of ministers and relating to public sector employment remained outside its jurisdiction. The FOI Act provided for some additional powers and limits in relation to matters appealed to the AAT or correction of records (see ss.56-57 FOI Act prior to 1 November 2011). Thus the Ombudsman was able to investigate complaints about agency decisions to deny or grant limited access to documents, the amount of fees and other charges ... delays in responding to requests or other administrative processes, and the adequacy and clarity of reasons for decisions' (Commonwealth Ombudsman 2006, pp. 3-4). This role reflected the more general role of the Ombudsman in 'ensuring agencies implement sound document management procedures, provide clear and accessible information, and are open and responsive to complaints about issues to do with access to information' (Commonwealth Ombudsman 2006, p. 4).

Despite these synergies between the Ombudsman's broader role and its role under the FOI Act, concerns remained (Commonwealth Ombudsman 2006, p. 5). The ALRC and ARC 'Open Government Report' considered that 'many of the

61 For example, to allow it to review decisions by Ministers under the FOI Act and to investigate complaints while an appeal to the AAT was pending, as well as having a role in AAT proceedings.

62 Responsibility for administration of the FOI Act, and the general monitoring and reporting requirements, has at times resided with the Department of Prime Minister and Cabinet, but is now back with the AttorneyGeneral's department. 
shortcomings of the [then] current operation and effectiveness of the Act can be attributed to this lack of a constant, independent monitor of and advocate for FOI' (ALRC, ARC 1995, pp. 61-62). They considered the most effective means of improving administration of the FOI Act would be the appointment of an FOI Commissioner. The commissioner would, on the basis of regular audits, monitor compliance with and administration of the act; promote the act; provide advice, assistance and facilitation to agencies and the public; provide legislative policy advice; and participate in broader information policy (ALRC, ARC 1995, pp. 63-69).

Importantly, however, the report recommended that the commissioner not be given investigatory powers to form a view as to the correctness of specific actions or decisions under the act, and no determinative powers to review an agencies FOI decision (ALRC, ARC 1995, pp. 69-70). The AAT would remain the sole reviewer of FOI decisions. The report considered that providing the commissioner with determinative powers would be incompatible with its role in developing guidelines, providing advice to agencies and, particularly, facilitating requests for disclosure. Conflicts of interest or erosion of the perception of independence could arise. Merits review was available by going to the AAT, and any criticisms of the practices of the AAT could be rectified without having to provide for another form of merits review (ALRC, ARC 1995, p. 70).

Additional reviews of the FOI Act by the Commonwealth Ombudsman in 1999 (Commonwealth Ombudsman 1999) and the Senate Legal and Constitutional Legislation Committee 2001 (SLCLC 2001) also encouraged the establishment of an FOI Commissioner, either as an independent body or, given resourcing constraints, as a specialised unit within the Ombudsman's Office. The 2004 review by the ANAO emphasised the lack of any government agency with responsibility to ensure general compliance with the FOI Act or to identify improvements both to the operation of the act or information collected (ANAO 2003, [2.30]). The ANAO recommended the Attorney-General's Department take a more active role in monitoring agency compliance (ANAO 2003, [2.29]). The most recent review of the Commonwealth Ombudsman in 2006 reiterated the need to establish a statutory FOI commissioner 'who would play an active role in publicising the legislation's existence, monitor compliance with its provisions and promote its effective operation' (Commonwealth Ombudsman 2006, p. 33).

Election commitments by the Labor party to reform FOI legislation in the lead up to the 2007 election included the establishment of an Office of the Information Commissioner and establishment of various statutory office holders to act along with the Privacy Commissioner to provide a 'clearing house for complaints, oversight, advice and reporting of freedom of information and privacy matters' 
(Rudd and Ludwig 2007, p. 6). These reforms were instituted by the Freedom of Information Amendment (Reform) Act 2010 (Cth) and the Australian Information Commissioner Act 2010 (Cth).

\section{Delays}

The most common complaint to the Ombudsman about the operation of the FOI Act related to delays in the processing of FOI requests (Commonwealth Ombudsman 2006). In general, an agency has 30 days to respond to an FOI request. If the request concerns a state government or another business or person requiring a 'reverse FOI' consultation the time limit can be extended to up to 60 days. The time limit can be extended for the time waiting for the applicant to respond to a notification about likely charges involved with the processing of their request. The Ombudsman's own motion investigations into administration of the FOI Act in 1999 and 2006 both concluded that there was, in general, excessive delays in responding to FOI requests, though these varied considerably between agencies. Alarmingly, the Ombudsman suggested that this was not just the result of the nature of the FOI requests or the allocation and efficient use of resources within the agency. As the 1999 'Needs to Know' report suggested,

the investigation also identified a more pervasive malaise in the administration of FOI: a growing culture of indifference or resentment towards the disclosure of information, ailing standards of training and development and a profound lack of understanding of or commitment to the ethos and purpose of the legislation. It appeared that, although the FOI Act had wrought some change in the culture of public administration, its goals had been imperfectly achieved. Many of the early FOI practitioners were advocates of open government, but had, over time, been replaced by staff who had grown up in a very different environment, with FOI just one of a number of competing demands on agency time and resources (Commonwealth Ombudsman 1999).

In the 2006 'Scrutinising Government' report, the situation had perhaps improved, but the complaints received by the Ombudsman, albeit a relatively small proportion of the total number of FOI requests (Commonwealth Ombudsman 2006, p. 9), ${ }^{63}$ still indicated that agencies were failing to allocate adequate resources, had developed a culture of 'compliant but protracted processing of FOI requests' (Commonwealth Ombudsman 2006, p. 15), and that 'good FOI administration is of dwindling importance, in some agencies at least' (Commonwealth Ombudsman

63 For example, in 2004 there were 275 complaints arising out of over 39,265 FOI requests. 
2006, p. 28). 'Moreover, there are proportionally more "other-than-personal" FOI requests taking more than 60 days to process than is the case for personal FOI requests' (Commonwealth Ombudsman 2006, p. 18). ${ }^{64}$

The recent amendments to the FOI Act provide for complaints to be investigated by the new Information Commissioner, or the Ombudsman where that is considered appropriate (where the complaint is part of a wider grievance about the agency, for example). The commissioner has powers similar to the ombudsman to make inquiries, obtain information from any person or inspect relevant documents, including exempt documents (see ss.79-82 FOI Act as amended). There is no formal power to compel agencies to resolve the complaint, however the commissioner can require the agency to provide particulars of any action it will take in response to the investigation (s.89 FOI Act as amended) and can then report to the relevant minister's and have the report tabled in Parliament. Like the Ombudsman, the Information Commissioner is only able to investigate complaints against agencies and not ministers (OAIC n.d.), [11.6]).

\section{Reviews}

The recent reforms go beyond the many recommendations for the creation of an Information Commissioner by giving that office the function of reviewing FOI decisions along with the other functions envisaged by the various recommendations. Applicants unhappy with the response to their request for access to documents can seek review by the Information Commissioner. It is intended that this will provide 'a simple, expedient and cost efficient system for external merits review', based mainly on the submissions and papers provided by the parties, rather than through formal hearings (Explanatory Memorandum, Freedom of Information Amendment (Reform) Bill 2010, p. 32). The commissioner can affirm, vary or set aside the original decision relating to access and substitute a new decision (s.55K FOI Act). Applicants who disagree with the Information Commissioner's decision can apply to the AAT for review (s.57A FOI Act). The commissioner can also refuse to review a matter and refer the review to the AAT where, for example, the commissioner has played a role in the dispute or it would more effectively resolve the dispute to do so (s.54W FOI Act). Importantly, in any review by the commissioner, the agency or Minister who made the initial decision relating to access to a document has to justify the position they took; there is no onus on the applicant to establish that the document should be released or the conditions of that release (s.55D FOI Act as amended). The commissioner is given various powers in relation to gaining access to documents and agencies have an obligation to assist the commissioner in carrying out the review (see generally Part VII FOI Act as amended).

64 In 2003-04, the respective proportions were in the order of 17 per cent and 12 per cent respectively. 
There is no cost to the applicant for review by the commissioner, ${ }^{65}$ and the intended informality of proceedings may also help to keep costs low, but there will remain considerable time and resource costs involved. It is unclear whether interposing a hopefully more cost efficient review by the commissioner before an appeal to the AAT will reduce the total costs of reviews. The concerns of the ALRC and ARC about the conferral of a review function on the commissioner remain: potential confusion about sources of review; potential delays before a final decision can be obtained given right of the agency or minister to appeal to the AAT; and potential conflict between the objectives of facilitating reform within agencies and acting as arbiter of disputes between agencies and individuals disgruntled with agency decisions. The role of the commissioner in working with agencies in relation to record-keeping, developing processes and policies in relation to proactive release of documents, and dealing with complaints through a process of investigation and reconciliation all require a considerable degree of goodwill between agencies and the commission. It will be a difficult balance to maintain that goodwill, particularly given the resistance of some agencies and the considerable resource costs they may be faced with, while also sitting in judgement of the response of agencies to access requests.

As John McMillan, now the Information Commissioner, commented on the 20-year anniversary of the enactment of the FOI Act, '[t]he cost to government of administering FOI requests poses an unresolvable dilemma' (McMillan 2002, p. 23). Responding to access requests imposes administrative burdens that divert resources from other activities. 'On the other hand, the success or failure of an FOI scheme can hinge on the issue of costs ... A high-costs regime can be used by government to deter requests and to corrode the spirit of an FOI Act' (McMillan 2002, p. 23).

In the first annual report on the operation of the FOI Act, it was stated:

It is not intended that the costs incurred under the Act should be offset by any revenue generating mechanism to recover costs. The Act does not seek, by means of the scheme of charges for access, to recover the full costs of meeting [FOI] requests. Most significantly, the Act provides that charges cannot be made for time spent in examining a document with a view to deciding whether the document contains exempt matter (Attorney-General's Department 1983, p. 143).

This view reflected the concern of the Senate Standing Committee's 1979 report that charges for decision-making time might be applied inconsistently or depend on the commitment to openness: 'It hardly seems fair or just, in a Bill designed to confer rights of access, that an agency's charges are inversely related to its commitment to the philosophy underlying the Bill' (SSCLCA 1987, [11.22]).

65 Appeals to the AAT will involve an application fee of $\$ 777$ as at 1 March 2011. 
Within three years (see Freedom of Information Law Amendment Act 1986 (Cth)), however, there was an application fee of $\$ 30$ and internal review charges, increases in the hourly charges for search and retrieval and, perhaps most significantly, a 'decision-making fee' of \$20 per hour for time spent by public servants in deciding whether to release information (Ardagh 1987, p. 22). There were exemptions for persons seeking personal income maintenance information - for example, information about pensions, government allowances, etc. and the ability to waive most fees requiring the agency or Minister to take into account 'whether the giving of access is in the general public interest or a substantial section of the public' ${ }^{66}$ The introduction of these charges were widely criticised: they went against the stated intention of the government not to introduce such charges; they would be a deterrent against lodging applications, particularly by those seeking policy information in the broader public interest; and they encouraged inefficient document handling and decision-making processes under the act (see, for example, Ardagh 1987, p. 23). It has been observed that the 1986 charges marked a turning point in the operation of the FOI Act, encouraging usage of the act to be dominated by access to personal records (McMillan 2002, pp. 23-24).

Even after the increase, the charges paid under the act were far exceeded by the estimated costs of complying with the FOI Act. For example, in 2009-10, \$211.612 was collected in fees for initial and internal review applications, amounting to 41 per cent of total FOI revenue. Agencies notified a total of $\$ 3,177,732$ in charges to applications, but through the exercise of their discretion to reduce or waive fees collected only $\$ 305,178$, or 10 per cent, of those charges. The total amount of fees and charges, however, only represented 1.9 per cent of the total costs reported in the annual report for the operation of the FOI Act (O'Connor, B., Minister for Privacy and Freedom of Information 2010). Over the 30 years of the FOI, reported fees and charges represent only 2.08 per cent of the estimated total costs of administering the FOI Act (OAIC 2012, p. 5).

\footnotetext{
66 Section 30A FOI Act allowed the agency or Minister to remit the fee for any reason, including that payment of the fee would cause financial hardship or giving of access in the general public interest or in the interest of a substantial section of the public. This section was abolished in the recent amendments and replaced by s.29(5) which makes it clear that in deciding whether to reduce or not impose the charge the Minister must take into account the same two factors. The Information Commissioner is also now able to review decisions relating to reducing the charges imposed.
} 


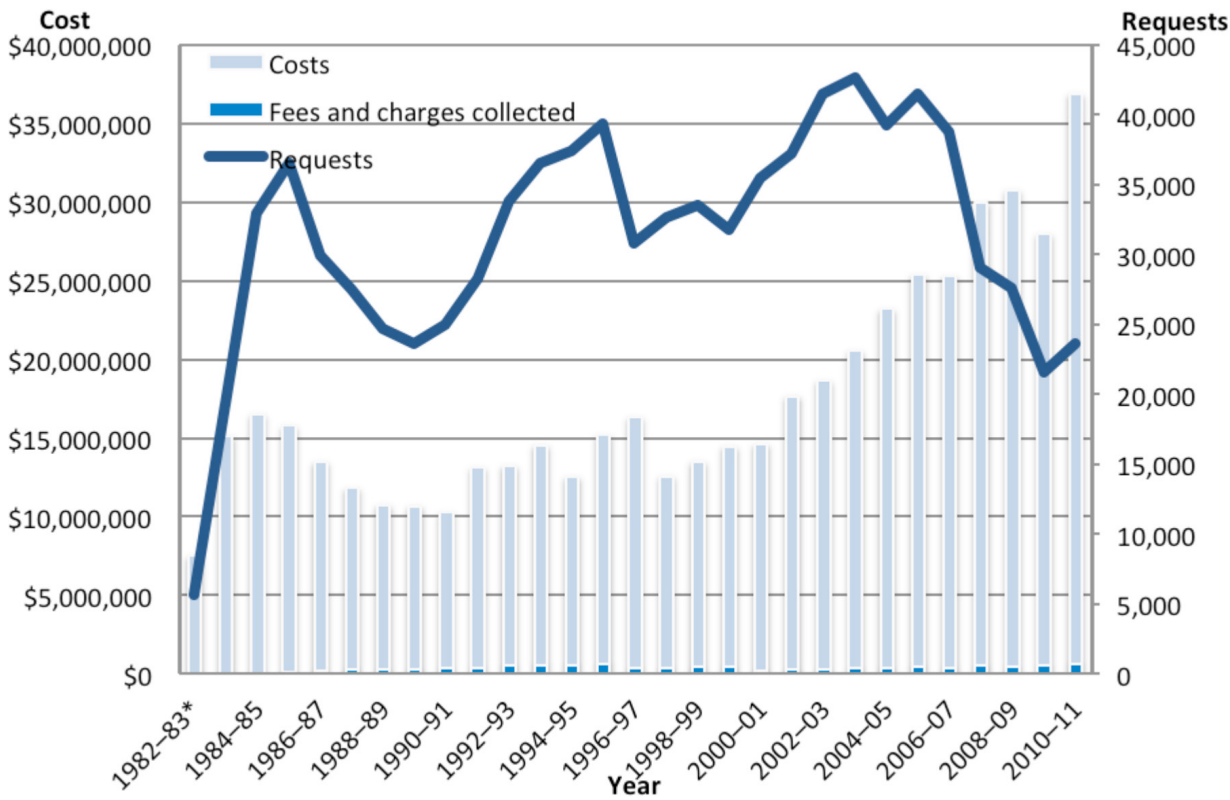

Figure 1: Costs and charges in relation to FOI requests

Source: OAIC 2012, p. $20 .^{67}$

The costs of administering the FOI Act are generally based on the percentages of staff time reportedly allocated to complying with the requirements under the Act. There is considerable variation in the costs per request between agencies ${ }^{68}$ and, as Figure 1 suggests, an increase in the raw figures over time despite a general decrease in requests in recent years. The high number of requests for personal information received by some agencies, the resources otherwise available to some agencies, and the level of interest in particular developments in any year all play a role. As the 1987 Senate Committee report suggested:

The introduction of the FOI Act formed part of a trend towards increasing openness in government. In turn, the Act has had an impact upon that trend. Some of the material released under the FOI Act would have been released even in the absence of the legislation. The Committee has no method of determining what proportion of FOI access requests are

67 Note that there was a change 'from using the average of the salary levels of the three agencies recording the highest total FOI costs in pre-2006-07 FOI annual reports to using Australian public service base salary median figures, and the inclusion of Senior Executive Service salary costs since 2006-07, means that tables, charts and appendices in FOI annual reports that contain pre-2006-07 salary cost components are not strictly comparable with their post-2005-06 equivalents' (Annual Report p. 21).

68 For example, in 2009-10 there were 11 agencies with an average cost per request received greater than $\$ 10,000$. 
for such material. But the proportion, at least in the area of applicants seeking access to personal or personnel files, would appear to be high (SSCLCA 1987, p. 15).

The report points out that calculating total and average costs of compliance with the FOI Act depends on many agency-specific factors, including the approach taken to providing access outside of the FOI Act, allocation of resources to complying with the FOI Act rather than general document and information handling procedures, and approaches to initial and internal decision-making (SSCLCA 1987, p. 15). Some material released, such as the disclosure of internal manuals, may also have benefits to the agency beyond compliance with the FOI Act. The committee noted, however, that the costs of the FOI Act extended beyond that reported by agencies, to include costs to information providers, costs of the tribunal and court systems to resolve FOI disputes, opportunity costs of the resources allocated to FOI matters, and possible costs of 'threatened or actual reduction in information flow to [the Commonwealth]' due to the possible disincentives created through the FOI Act (SSCLCA 1987, p. 28). Though the published information about costs must be 'treated with some caution', the committee was prepared to assume that the omissions and deficiencies could 'cancel each other out' (SSCLCA 1987, p. 33).

Against those costs the committee attempted to compare the (admittedly unquantifiable) benefits of the legislation. They described how some agencies had reported greater awareness of the need for objectivity in dealing with the public, improved quality of decision-making, improved communications with and understanding of clients, improved efficiency of records management and greater public awareness of the role of the agency (SSCLCA 1987, p. 19). Disclosure under the FOI Act could lead to changing what would otherwise have been a 'poor decision', benefits to news reporting, assistance in claiming personal, business or professional benefits provided by the government, and increased certainty over how access was provided all potentially involved considerable benefits to the recipients of the information and the public at large. The committee concluded that the benefits of FOI were considerable, but that attention had to continue to be paid to the costs of the operation and administration of the FOI Act (SSCLCA 1987, p. 33).

The 2010 amendments to the FOI Act altered the fee structure again. All application fees, including fees for internal review, have been abolished. There are no costs to access your personal information. In line with a greater emphasis on reducing delays in the processing of requests, all charges will be waived if a statutory timeframe is not met (Freedom of Information Amendment (Reform) Act 2010 (Cth)). The introduction of the IPS and disclosure logs are also intended to reduce the number and nature of individual requests (OAIC n.d., [13.65] 
and [14.4]). Finally, the role of the Information Commissioner in developing government information policy, including the role of government information as a national resource, will include information handling and processing reforms.

The fee structure was subject to review a little over a year after its amendment, with the OAIC recommending significant changes to the charges framework (OAIC 2012). The review is based on the role of government in meeting a substantial part of the costs of what it terms a democratic right, but seeks to use charges as an incentive to moderate unmanageable requests and simplify access processes even further. The review makes 10 recommendations, including various ways to simplify the types and calculation of charges and circumstances for waiver of charges, but there are perhaps two main aspects to the suggested changes.

The first suggested change comes from recognition that there are many, largely informal, ways in which information is provided on request. Agencies would be encouraged to more clearly identify these administrative access schemes on the agency's website where information that is open to release under the FOI Act could be obtained largely free of charge. Anyone not satisfied with the response to a request under the administrative access scheme could then make a formal request under the FOI Act. Bypassing the administrative access scheme by making a request under the FOI Act for information that could have been obtained under the access scheme will lead to an application fee being imposed (OAIC 2012, pp. 59-60).

The second suggested change stems from a concern that some agencies face a substantial administrative burden in handling large and complex requests, particularly where access under the FOI Act is being used as a substitute for other forms of access (such as the discovery process in litigation, see OAIC 2012, pp. 69-70). Under the FOI Act, agencies can refuse a request if satisfied that it would 'substantially and unreasonably divert the resources of the agency from its other operations' (ss.24 and 24AA FOI Act).${ }^{69}$ Before refusing the request, the agency has to consult with the applicant about possibly revising the request (s.24B FOI Act). It has been emphasised that this discretion to refuse access on the basis of resource costs can only be used in strict circumstances, and not merely because of the costs of inefficient record-keeping or the number of documents potentially in issue (OAIC n.d., 'FOI Guidelines', [3.47]). However, agencies have regarded the discretion as imprecise or indeterminate and have preferred to rely on the setting of high fees to encourage further discussion about the scope of requests (OAIC 2012, p. 69). The review therefore suggests

69 Note that agencies can treat multiple requests for the same documents or relating to the same subject matter as a single request (s.24(2) FOI Act). 
that greater certainty be introduced through the imposition of a cap of 40 hours on the processing time for a request before it can be refused (OAIC 2012, pp. 68-70).

\section{Conclusions}

As John McMillan has suggested, 'the fee scale alone will not hold the balance between the democratic potential of FOI and the cost to government' (McMillan 2002, p. 24): much depends on the attitude of the agency to the request. Any objective to promote disclosure of information at the lowest reasonable cost

can only be realised fully if in the administration of the Act there is a recognition (and quantification, roughly speaking) of all the intangibles that bear upon the true 'cost' of an FOI request: the democratic principles that underpin the FOI Act, the public interest purpose (if any) to which the requested information may be put, the reasonableness (or otherwise) of the agency and an applicant consulting about or shaping the request, and whether the resource burden of a particular request is attributable more to the unsatisfactory nature of file management or FOI processing in an agency than to the nature of the request (McMillan 2002, p. 25).

The recent amendments reflect this concern with information management. The expanded role of proactive disclosure under the IPS, and assisting access through disclosure logs both are instances of the increased emphasis on information management. As the amended objects clause now states, information held by the government is to be managed for public purposes, and is a national resource (s.3(3) FOI Act). The emphasis on ready release of information is further emphasised in the review of FOI charges suggestions to further encourage informal access regimes and place caps on processing time.

In many ways this emphasis on information management may facilitate the change of culture that is seen as essential to fulfilling the objectives of the FOI Act. Reducing the costs associated with fulfilling FOI requests while enhancing the means by which an agency can communicate with the public provides an added incentive to facilitate access generally. However, the emphasis on information management may serve to only highlight the distinctive treatment of personal or non-sensitive requests and those that have the potential to be embarrassing to the government. 


\section{Conclusion: The impact of FOI?}

In May 1980, federal Cabinet met to decide on the government's response to the Senate Standing Committee's report on the Freedom of Information Bill. It was a meeting which would shape FOI laws in Australia for the next three decades. Before Cabinet was a submission reporting on the views of the most influential government departments. They all opposed extending disclosure beyond the limited amount already provided for by the FOI Bill 1978. ${ }^{70}$

The Finance Department, led by Ian Castles, was concerned about the significant cost implications of the Bill, and was opposed 'as a matter of principle, to the proposal to appoint a "Referee"' (the AAT). Treasury, through its Secretary John Stone, warned that 'Ministers should be left in no doubt whatsoever as to the cost and resource implications'. With Finance, they suggested that 'the final decision on whether to release confidential commercial information should rest with the suppliers', who would 'be the best judge of whether its release would be harmful to [their] own commercial interests'. For the Department of Prime Minister and Cabinet, the Bill as it stood already represented 'a major innovation, with significant though unquantifiable costs and major administrative difficulties'. Appointing an external referee to review claims to exemption would 'add an unnecessary new layer of review to the existing mechanisms' and any appeal should rest with the Minister. The chairman of the Public Service Board commented that 'Ministers might find this a suitable occasion to review the whole subject'.

They were right, and wrong, about the implications of the FOI Act. Costs and resource implications would indeed continue to influence the operation of the FOI Act. Commercial concerns under the act would continue and incorporate those of the private individual. However their concern that an external referee would threaten the role of government departments in our system of ministerial responsibility is less apparent. As the 1987 Senate Standing Committee report would suggest, any concern about loss of candour or the quality of advice had diminished with the realisation that, 'as a result of the way courts and the tribunal have interpreted the FOI Act, public servants have become increasingly confident that the Act provides sufficient protection' (SSCLCA 1987, [2.71]).

The FOI Act has generally been credited with significantly enhancing the openness and transparency of government.

\footnotetext{
70 See Cabinet Submission No. 3938: Freedom of Information Bill 1978 — report of Senate Standing Committee on Constitutional and Legal Affairs — Related to Decision No. 11134, 11653, 12437, 11185(Ad Hoc), 11610(Ad Hoc), 11623, 11632(Ad Hoc) part of series A12909, 1980, pp. 77-80. Available at http:// recordsearch.naa.gov.au/scripts/Imagine.asp? B=30484359.
} 
There can be no doubt that Australian government today is considerably more open than it was when FOI laws were first considered during the later part of the 1970s. Freedom of information has both been part of, and underpinned, broader changes. These have included changes in doctrines of public law that have brought it more into line with the traditional openness of courts, changes in the framework and practices of government, and more complex philosophies of government. The fact that freedom of information makes disclosure possible and that disclosure may be politically embarrassing means that governments now need to think more carefully about the consequences of their actions. At the same time, it has increased community awareness about government actions and made the community more demanding of explanations about situations touching on probity and propriety in government (Paterson 2005).

The ALRC and ARC 'Open Government Report' states that the enactment of the FOI Act in 1982 brought about a 'fundamental change in the law in Australia relating to access to government-held information and challenged the boundaries of government secrecy' (ALRC, ARC 1995, p. 11). The FOI Act

has had a marked impact on the way agencies make decision and the way they record information. Along with other elements of the administrative law package, the FOI Act has focused decision-makers' minds on the need to base information on relevant factors and to record the decision making process. The knowledge that decisions and processes are open to scrutiny, including under the FOI Act, imposes a constant discipline on the public sector (ALRC, ARC 1995, pp. 15-16).

But the report then suggests that the 'assessment is not entirely positive ... There is a perception ... that the Act is not achieving its objectives' (ALRC, ARC 1995, pp. 15-16). Subsequent reviews have confirmed the impression that the FOI may work well in facilitating access to personal information, but not so well in providing access to policy-related information (Commonwealth Ombudsman 2006, p. 1).

The Commonwealth government is clearly much more open than at the time FOI legislation was being considered. The role of the FOI Act, however, remains difficult to isolate. The trend towards openness was already evident as the FOI Act was being introduced - indeed it was an important part of the acceptance of the obligations the FOI Act imposed. Courts had already cast doubt on any presumption of the government-determined need for secrecy, and other administrative law amendments, both in legislation and by the courts, soon had a profound influence on decisions affecting individual interests. Recognition of 
the constitutional protection of representative government followed, although it never reached the point of securing any right to government disclosure in the absence of statutory provision.

However, the application and interpretation of the FOI Act arguably did not follow that judicial trend. Emphasis on the need for balance reflected in the structure and drafting of the FOI Act conferred extensive discretion on agencies and ministers to withhold information from disclosure. Concerns over the impact of disclosure on the internal deliberations of government extended exceptions and justified certificates preventing disclosure. The uncertain and intangible public interest in disclosure was subjected to the concerns of those charged with administering the Act.

Government has continued to evolve. Emphasis on the commercial concerns both of and in relationship with government was reflected in the FOI Act's protection of those interests. The inherent tension between privacy interests and open disclosure was increasingly tightened one way through the introduction of legislative protection and a statutory agency devoted to monitoring, enforcement and encouragement of privacy interests.

An officer to champion greater openness in government has come only with the most recent reforms to the FOI Act. Up until now, access to government information has largely come at the initiative of the individual, primarily through seeking information personal to them or the organisations they represent. Proactive disclosure has been limited along with systematic attempts to improve the document and information handling of government. Delays in responding to requests and providing information, attitudes to the application of exemptions, and the imposition of, albeit largely potential, charges and fees have all contributed to discourage the pursuit of information in the public interest. It remains to be seen whether the current emphasis on proactive disclosure and efficient access will bring with it a heightened willingness to disclose sensitive or embarrassing material.

The theme common to much of the discussion in this chapter has been the effect of the FOI Act on the relationship between government, the public service, and the public. The impact of government disclosure laws depend on the political and constitutional climate in which they operate. At the Commonwealth level, concerns over the impact of FOI legislation on our system of responsible government have continued to be raised by those subjected to FOI obligations. Subjecting agencies to individual scrutiny distinguishes their role in policy development and implementation, multiplying avenues and opportunities for allocating responsibility. Perhaps, in the process, this increased separation between agencies and their ministers serves to reduce the influence of those agencies and the public service in general, affecting their role in the policy- 
making process and the effectiveness in turn of the FOI Act in holding that process to account. The potential operation of the FOI Act has therefore been resisted as agencies side with ministers in the competition with the public over access to the inner workings of government. Information, instead of being a resource available to all in an effort to generate and improve policy, remains used as currency to gain or maintain political favour.

The recent amendments to the FOI Act in many ways reflect recommendations made before the FOI Act was first enacted. They reflect the view that greater disclosure of government information has the potential to enhance the discussion among all participants in the policy-making process, which in turn places responsibility on all of those participants to make use of that information appropriately. It remains to be seen whether the amendments go far enough for the FOI Act to realise this potential.

\section{References}

Ackerman, J. and I. Sanoval-Ballesteros 2006, 'The Global Explosion of Freedom of Information Laws', AdministrativeLaw Review 58.

Administrative Review Council 1998, 'The Contracting Out of Government Services', Report No. 42. Available at: http://www.arc.ag.gov.au/Publications/ Reports/Pages/Reportfiles/ReportNo42.aspx.

The Age 2010, 'Transcript of Julia Gillard's Announcement', 7 September 2010. Available at: http://m.theage.com.au/federal-election/transcript-of-juliagillards-announcement-20100907-14zhs.html.

Ardagh, A. 1987, 'The Walls of Secrecy are Going Up Again', Legal Service Bulletin 12. ,

Aronson, M. 2005, 'Is the ADJR Act Hampering the Development of Australian Administrative Law?' Australian Journal of Administrative Law 12.

Attorney-General's Department 1983, 'Annual Report on the Operation of the Freedom of Information Act 1982 for the period 1 December 1982 to 30 June 1983', AGPS.

Attorney-General's Department 2010, 'Intellectual Property Principles for Australian Government Agencies' . Available at: http://www.ag.gov.au/www/ agd/agd.nsf/Page/Copyright_CommonwealthCopyrightAdministration_ StatementofIPPrinciplesfor AustralianGovernmentAgencies. 
Attorney-General's Department 2012, 'Review of NBN Compliance with FOI', 16 April 2012. Available at: http://www.ag.gov.au/ Consultationsreformsandreviews/Pages/Review-of-NBN-compliance-withFOI.aspx.

Australian Government n.d., 'Publishing Public Sector Information'. Available at: http://webguide.gov.au/.

Australian Labor Party 1972, 'It's Time', speech by the Leader of the Opposition, 13 November 1972.

Australia's Right to Know Coalition 2011, 'Response to the Discussion Paper: Disclosure Logs, Office of the Australian Information Commissioner', 28 March 2011.

ALRC (Australian Law Reform Commission) 2010, 'Secrecy Laws and Open Government in Australia', Report No. 112, 17 September.

ALRC, ARC (Australian Law Reform Commission, Administrative Review Council) 1995, 'Open Government: A review of the federal Freedom of Information Act 1982', Report No. 77.

ANAO (Australian National Audit Office) 2003, 'Audit Report No. 57, 2003-2004: Administration of freedom of information requests'.

Bayne, P. and K. Rubenstein 1995, 'The Objects of the Freedom of Information (FOI) Acts and their Interpretation', Australian Journal of Administrative Law, 2.

BBC News 2010, 'US Embassy Cables: The background', 29 November 2010. Available at: http://www.bbc.co.uk/news/world-us-canada-11862320.

Benkler, Y. 2011, 'A Free Irresponsible Press: Wikileaks and the battle over the soul of the networked fourth estate'. Available at: http://benkler.org/ Benkler_Wikileaks_current.pdf.

Bland Committee 1973, 'Final Report of the Committee on Administrative Discretions', Parliamentary Paper No. 316.

Blenkin, M. 2011, 'How 1980 Marked a Turning Point to Reform', The Age, 1 January 2011. Available at: http://news.theage.com.au/breaking-newsnational/how-1980-marked-a-turning-point-to-reform-20110101-19c70. html.

Bovens, M. 2002, 'Information Rights: Citizenship in the information society' Journal of Political Philosophy 10. 
Brown, A. J. 2007, 'Privacy and Public Interest Disclosures: When is it reasonable to protect whistleblowing to the media?', Privacy Law Bulletin 4.

Brown, A. J. (ed) 2008, Whistleblowing in the Australian Public Sector: Enhancing the theory and practice of internal witness management in public sector organisations, ANU E Press, Canberra.

Brown, A. J. 2011, 'Courage Needed to Protect Whistleblowers', The Australian, 24 June 2011. Available at: http://www.theaustralian.com.au/ business/legal-affairs/courage-needed-to-protect-whistleblowers/storye6frg986-1226080859231.

Brown, A. and P. Latimer 2011, 'Whistleblower Legislation in Australia: Analysis and reform', in M. Arszulowicz and W. W. Gasparski (eds), Whistleblowing: In defence of proper action, Transaction, New Brunswick.

Cane, P. and L. McDonald 2008, Principles of Administrative Law: Legal regulation of governance, Oxford University Press, Oxford.

CARC (Commonwealth Administrative Review Committee) 1971, 'Report', Parliamentary Paper No. 144.

CLRC (Copyright Law Reform Commission) 2005, 'Crown Copyright Report'.

Commonwealth Ombudsman 1999, "Needs to Know": Report on the investigation of administration of FOI in Commonwealth agencies'.

Commonwealth Ombudsman 2006, "Scrutinising Government": Administration of the Freedom of Information Act 1982 in Australian government agencies', March.

Costello P., Treasurer 2007, 'Questions in Writing: Freedom of Information', House of Representatives, Debates, 20 March 2007.

Creyke, R. and J. McMillan (eds) 1998, The Kerr Vision of Australian Administrative Law: At the twenty-five year mark, Centre for International and Public Law, ANU, Canberra.

Creyke, R. and J. McMillan 2009, Control of Government Action: Text, cases and commentary, 2nd ed., Lexis Nexis Butterworths, Chatswood.

Crozier, R. 2011, 'Greens Win NBN Co FOI Review', itnews, 25 March 2011. Available at: http://www.itnews.com.au/News/252354,greens-win-nbn-cofoi-review.aspx. 
Department of Finance and Deregulation n.d., 'Listing of Contract Details on the Internet (Meeting the Senate Order on Departmental and Agency Contracts): Financial management guide $8^{\prime}$.

Department of Finance and Deregulation 1997, 'Governance Arrangements for Commonwealth Government Business Enterprises'.

Department of Finance and Deregulation 2008, 'Declaration of Open Government'. Available at: http:/www.finance.gov.au/e-government/ strategy-and-governance/gov2/declaration-of-open-government.html.

Department of the Prime Minister and Cabinet n.d., 'Ahead of the Game: Blueprint for reform of Australian government administration'. Available at: http://www.dpmc.gov.au/publications/aga_reform/aga_reform_blueprint/ index.cfm\#blueprint.

Ellicott Committee 1973, 'Report of the Committee of Review of Prerogative Writ Procedure', Parliamentary Paper No. 56.

Finn, C. 2003, 'Rethinking Commercial Confidentiality in the Decade of Competition Policy', Freedom of Information Review 106.

Fraser, J. M. 1978, 'Responsibility in Government' Australian Journal of Public Administration 37.

Freiberg, A. 2010, The Tools of Regulation, Federation Press, Sydney.

Grattan, M. 2005, 'Yes, Minister: Your will is my command', The Age, 6 July 2005. Available at: http://www.theage.com.au/news/michelle-grattan/yesminister-your-will-is-my-command/2005/07/05/1120329444456.html.

Grattan, M. and C. Yeates 2010, 'Xenophon Deal advances NBN', The Age, 25 November 2010. Available at: http://www.theage.com.au/technology/ technology-news/xenophon-deal-advances-nbn-20101124-187e8.html.

Government 2.0 Taskforce 2009, 'Engage: Getting on with government 2.0'. Available at: http://www.finance.gov.au/publications/gov20taskforcereport/ index.html.

Gurry, F. 1984, Breach of Confidence, Oxford University Press, Oxford.

Hazell, R., B. Worthy and M. Glover 2010, The Impact of of the Freedom of Information Act on Central Government in the UK: Does FOI work?, Palgrave MacMillan, Basingstroke.

Hood, C. 1991, 'A Public Management for all seasons?', Public Administration $69(1)$. 
itnews 2010, 'The NBN Co Business plan at a glance', 20 December 2010. Available at: http://www.itnews.com.au/News/242325, the-nbn-co-businessplan-at-a-glance.aspx.

Julnes, P. and M. Holzer 2001, 'Promoting the Utilization of Performance Measures in Public Organizations: An empirical study of factors affecting adoption and implementation', Public Administration Review, 61(6).

Kettl, D. F. 2000, 'Public Administration at the Millennium: The state of the field', Journal of Public Administration Research and Theory 10.

Lamble, S. 2002, 'Freedom of Information: A Finnish clergyman's gift to democracy', Freedom of Information Review 97.

Massola, J. 2011, 'Julia Gillard Backs FOI Exemption for Taxpayer Funded NBN', The Australian, 18 January 2011. Available at: http://www.theaustralian. com.au/national-affairs/julia-gillard-backs-foi-exemption-for-taxpayerfunded-nbn/story-fn59niix-1225990173260.

McMillan, J. 2000, 'Parliament and Administrative Law', Research Paper No. 13, 2000-01, Department of the Parliamentary Library.

McMillan, J. 2002, 'Twenty Years of Open Government: What have we learnt?', Inaugural Professorial Address: Administrative Law, ANU, 4 March.

Mendel, T. 2008, Freedom of Information: A comparative legal survey, 2 nd ed. UNESCO, Paris.

Moynihan, D. P. and S. K. Pandey 2004, 'Testing How Management Matters in an Era of Government by Performance Management', Journal of Public Administration Research and Theory, 15(3), pp. 421-439.

Mulgan, R. 2003, Holding Power to Account: Accountability in modern democracies, Palgrave MacMillan, Basingstroke.

OAIC (Office of the Australian Information Commissioner) n.d., 'FOI Guidelines'. Available at: http://www.oaic.gov.au/publications/guidelines.html.

OAIC 2012, 'Review of Charges under the Freedom of Information Act 1982'.

Oakes, L. 2005, 'Pillars of Democracy Depend on Leaks', The Bulletin/National Nine News, 24 August 2005.

O'Connor, B., Minister for Privacy and Freedom of Information 2010, 'Freedom of Information Act 1982: Annual Report 2009-2010'. 
OpenAustralia 2011, 'House debates: Tuesday, 1 March 2011: Telecommunications Legislation Amendment (National Broadband Network Measures - Access Arrangements) Bill 2010: Consideration in Detail'. Available at: http://www. openaustralia.org/debate/?id=2011-03-01.77.1.

Parker, C. and J. Braithwaite 2003, 'Regulation', in P. Cane and M. Tushnet (eds), The Oxford Handbook of Legal Studies, Oxford University Press, Oxford.

Parliamentary Library 2008, ‘Bills Digest: Freedom of Information (Removal of Conclusive Certificates and Other Measures) Bill 2008'. Available at: http:// www.aph.gov.au/library/pubs/bd/2008-09/09bd105.htm\#_ftn10.

Paterson, M. 2004, 'Commercial in Confidence and Public Accountability: Achieving a new balance in the contract state', Australian Business Law Review 32.

Paterson, M. 2005, Freedom of Information and Privacy in Australia: Government and information access in the modern state, Lexis Nexis Butterworths, Chatswood.

Prime Minister, Treasurer, Minister for Finance and Minister for Broadband 2009, 'New National Broadband Network', Press release, 7 April 2009.

Riley, J. 2010, 'Conroy survives Gag; Mr X, Fielding on side', IT Wire, 18 November 2010. Available at: http://www.itwire.com/it-policy-news/ government-tech-policy/43299-conroy-survives-gag-mr-x-fielding-on-side.

Roberts, A. 2001, 'Structural Pluralism and the Right to Information', University of Toronto Law Journal 51.

Rosanvallon, P. 2008, Counter Democracy: Politics in an age of distrust, Cambridge University Press, Cambridge.

Roxon N. 2012, 'Review of NBN Compliance with FOI', Media Release, 16 April 2012. Available at: http://www.attorneygeneral.gov.au/media-releases/ pages/2012/second\%20quarter/16-april-2012---review-of-nbn-compliancewith-foi.aspx.

RCAGA (Royal Commission on Australian Government Administration) 1976, 'Report', Chairman: H. C. Coombs, AGPS, Canberra.

Rudd, K. and J. Ludwig 2007, 'Government Information: Restoring trust and integrity', Policy Document, October 2007.

Sear, J. 2011, 'Restricting Freedom of Information Revelations', Crikey, 11 April 2011. Available at: http://blogs.crikey.com.au/purepoison/2011/04/11/ restricting-freedom-of-information-revelations/. 
Shane, S. 2010, 'Keeping Secrets Wikisafe', New York Times, 11 December 2010.

Shergold, P. 2006. 'Pride in the Public Service', speech delivered at the National Press Club, Canberra, 15 February 2006. Available at: http://www.pmc.gov. $\mathrm{au} / \mathrm{speeches} /$ shergold/pride_in_public_service_2006-02-15.cfm.

Skeketee, M. 2011. 'How Laurie Oakes Trumped John Howard', The Australian, 1 January 2011. Available at: http://www.theaustralian.com. au/in-depth/cabinet-papers/how-laurie-oakes-trumped-john-howard/storyfn7f6f9t-1225979649015.

SLCLC (Senate Legal and Constitutional Legislation Committee) 2001, 'Enquiry into the Freedom of Information Amendment (Open Government) Bill 2000', April 2001.

Snell, R. 2004, 'Conclusive or Ministerial certificates: An almost invisible blight on FOI practice', Freedom of Information Review 109.

Spigelman, J. 2010, 'The Centrality of Jurisdictional Error', Public Law Review 21.

SSCICMI(Senate Select Committee for an Inquiry into a Certain Maritime Incident) 2002, 'A Certain Maritime Incident'. Available at: http://www.aph.gov.au/ Parliamentary_Business/Committees/Senate_Committees?url=maritime_ incident_ctte/report/index.htm.

SSCLCA (Senate Standing Committee on Legal and Constitutional Affairs) 1979, 'Freedom of Information: Report by the Senate Standing Committee on Constitutional and Legal Affairs on the Freedom of Information Bill 1978, and aspects of the Archives Bill 1978'.

SSCLCA 1987, 'Freedom of Information Act 1982: Report on the operation and administration of the Freedom of Information Legislation'.

Stewart, A., P. Griffith and J. Bannister 2010, Intellectual Property in Australia, 4th ed., Lexis Nexis Butterworths, Chatswood.

Taggart M. 1997, 'The Province of Administrative Law Determined?', in M. Taggart (ed.), The Province of Administrative Law, Hart Publishing, Oxford.

Terrill, G. 1998, 'The Rise and Decline of FOI in Australia', in G. Terrill and A. McDonald (eds), Open Government, Macmillan Press, London.

Terrill, G. 2000, Secrecy and Openness: The federal government from Menzies to Whitlam and beyond, Melbourne University Press, Melbourne. 
Timmins, P. 2006, 'No Paper Trail if Possilbe', 5 February. Available at: http:// foi-privacy.blogspot.com.au/2006/02/no-paper-trail-if-possilbe.html\#. VBuAjyg4Z4g.

US Department of Defence 2010, 'DOD News Briefing with Secretary Gates and Adm. Mullen from the Pentagon', 30 November 2010. Available at: http:// www.defense.gov/transcripts/transcript.aspx?transcriptid $=4728$.

Whitlam, G. 1985, The Whitlam Government, 1972-1975, Penguin Books, Ringwood.

Wilson, L. 2010, 'NBN Study "Highly Sensitive"”', The Australian, 20 November 2010. Available at: http://www.theaustralian.com.au/news/nation/nbnstudy-highly-sensitive/story-e6frg6nf-1225956833353.

Wikipedia n.d., 'The Bed of Nails (Yes Minister)'. Available at: http:// en.wikipedia.org/wiki/The_Bed_of_Nails_(Yes_Minister).

Wilenski, P. 1988, Public Power and Public Administration, Hale \& Iremonger in association with the Royal Australian Institute of Public Administration, Sydney.

Worthy, B. 2010, 'More Open But Not More Trusted?: The effect of the Freedom of Information Act 2000 on the United Kingdom central government', Governance 23.

Worthy, B. and R. Hazell 2010, Assessing the Performance of Freedom of Information', Government Information Quarterly 27. 
This text taken from New Accountabilities, New Challenges, edited by John Wanna, Evert A. Lindquist and Penelope Marshall, published 2015 by ANU Press, The Australian National University, Canberra, Australia. 